\title{
Types and Amounts of Nonnutritive Sweeteners Purchased by US Households: A Comparison of 2002 and 2018 Nielsen Homescan Purchases
}

\author{
Elizabeth K. Dunford, PhD; Donna R. Miles, PhD; Shu Wen Ng, PhD; Barry Popkin, PhD
}

\author{
ARTICLE INFORMATION \\ Article history: \\ Submitted 4 February 2020 \\ Accepted 24 April 2020 \\ Available online 29 July 2020

\section{Keywords:} \\ Caloric sweetener \\ Nonnutritive sweetener \\ Processed foods \\ Food supply \\ Supplementary materials: \\ Figures 1, 2, and 7 and Tables 2, 3, 4, 5, and 6 are \\ available at www.jandonline.org. Podcast available \\ at www.jandonline.org/content/podcast.
}

\begin{abstract}
Background Purchases of foods containing nonnutritive sweetener (NNS) alone or in combination with caloric sweeteners (CS) has increased in recent years in the United States. At the same time clinical evidence is emerging of different cardiometabolic effects of each NNS type.

Objective To examine the prevalence and volume purchased of commonly consumed types of NNS in packaged food and beverage products comparing 2002 and 2018 using data from nationally representative samples of US households.

Participants/setting Nielsen Homescan Consumer Panels (The Nielsen Company); 2002 and 2018.

Main outcome measures Prevalence and volume of foods and beverages purchased containing CS, NNS, both CS and NNS, or neither CS nor NNS, as well as prevalence and volume of products containing specific NNS types.

Statistical analyses performed Differences examined using Student $t$ test, $P$ value of $<.05$ considered significant.

Results Volume of products purchased containing CS decreased comparing 2002 and 2018 (436.6 \pm 1.6 to $362.4 \pm 1.3 \mathrm{~g} / \mathrm{d} ; P<.05)$, yet increased for products containing both CS and NNS (10.8-36.2 g/d; $P<.05)$. Regarding specific types of NNS, changes were noted in the prevalence of households purchasing products containing saccharin $(1.3 \%$ $1.1 \% ; P<.05)$, aspartame (60.0\%-49.4\%; $P<.05)$, rebaudioside $A(0.1 \%-25.9 \%)$ and sucralose (38.7\%-71.0\%). Non-Hispanic whites purchased twice the volume of products containing NNS compared to Hispanics and non-Hispanic blacks in both years. Beverages were predominantly responsible for larger volume per capita purchases of products containing only NNS as well as both CS and NNS.

Conclusions A decline in purchases of products containing CS occurred in tandem with an increase in purchases of products containing both CS and NNS, along with a large shift in the specific types of NNS being purchased by US households. New NNS types enter the market regularly, and it is important to monitor changes in the amount of NNS and products containing NNS that consumers purchase.

J Acad Nutr Diet. 2020;120(10):1662-1671.
\end{abstract}

HE UNITED STATES HAS ONE OF THE HIGHEST INtakes of sugar globally, ${ }^{1}$ and a significant proportion of packaged bar-coded foods in the United States contain some type of caloric sweetener (CS)., ${ }^{2,3}$ Alongside this, interest from consumers and the food industry in reducing sugar consumption (and pressure from health-related bodies such as the World Health Organization) have led to an increase in intake of nonnutritive sweeteners (NNS; also termed artificial, low-calorie, or nonsugar sweeteners $)^{4-6}$ and wider availability of food products containing NNS. ${ }^{7}$ Prevention policies such as sugar-sweetened beverage taxes and front-of-package labels may also be incentivizing companies to utilize NNS as a way of reducing CS.,8 In 2012, $>40 \%$ of American adults and $>20 \%$ of American children reported consuming NNS on a daily basis compared with $30 \%$ in $2008 .^{9}$ Based on sales data, purchases of foods containing either NNS alone or in combination with CS has increased dramatically over the past decade in the United States. ${ }^{10}$ Moreover, a growing number of different types of NNS have become 
available in the US food supply, with new variants of NNS appearing on the market each year.

Although the intake of added sugars, and sugar-sweetened beverages in particular, is commonly associated with poor health outcomes, ${ }^{11,12}$ the association between NNS consumption and adverse health outcomes has remained relatively controversial in the academic literature. ${ }^{13,14} \mathrm{~A}$ number of cohort studies have linked NNS consumption to increased body weight, type 2 diabetes, and other adverse cardiometabolic outcomes, but literature with the same cohorts has found the opposite effect when controlling for many measurement and causality issues linked with NNS used. $^{12,13,15,16}$ In addition, results from randomized controlled trials (RCTs) have failed to demonstrate a relationship between NNS and energy intake or increased consumption of sweet foods. ${ }^{17,18}$ However, previous RCTs and meta-analyses have generally categorized all NNS together and have not examined differences in the effect of specific types of NNS on health outcomes, energy intake, or body weight, and the RCT of Higgins and Mattes suggests heterogeneity in health impacts of different NNS types. ${ }^{19}$

Both research and policy recommendations generally group all NNS together, suggesting that each type of NNS has the same effect on appetite, energy intake, and body weight. $^{19}$ However, not only does each NNS have its own unique chemical structure and therefore sensory properties (eg, sweetener intensities, mouth feel), a recent RCT that examined the effects of 4 commonly consumed NNS in the United States on body weight found differential responses between NNS types, indicating that consumption likely has effects beyond the contribution of sweetness to food and beverage products. ${ }^{19}$ In particular, saccharin was found to significantly increase body weight, but aspartame, rebaudioside $A$ (reb-A, which is predominantly found in stevia), and sucralose resulted in greater weight loss.

In this context, comprehensive nutrient databases capable of capturing newly introduced or reformulated products in the US food and beverage supply are critical to capture changes to both the amount and type of NNS to which consumers are exposed..$^{20}$ The level of NNS is not required to be displayed on nutrition labels in the United States, so obtaining accurate and direct measures of the concentration of different types of NNS in the food supply is problematic. ${ }^{10}$ Alongside this, the US Department of Agriculture food composition tables are not updated frequently enough to capture the ongoing rapidly occurring changes in the food supply. Studies using data from the National Health and Nutrition Examination Surveys can only capture consumption of about 7,600 unique foods from over 85,000 products with unique formulations that US consumers purchase each year. ${ }^{7,21}$ As a consequence, studies examining consumption of NNS generally rely on non-ingredient specific keywords, such as "low calorie," to identify foods containing NNS. To the knowledge of the authors, no studies to date have examined the extent to which individual types of NNS are purchased and consumed by the US population.

In this study, the prevalence and volume purchased of commonly consumed types of NNS in packaged food and beverage products is examined using data from a nationally representative sample of US households. Comparisons between 2002 and 2018 among the types and volume of each NNS purchased by US consumers are analyzed to examine

\section{RESEARCH SNAPSHOT}

Research Question: Has the prevalence and volume purchased of commonly consumed types of NNS in packaged food and beverage products changed between 2002 and 2018 in the United States?

Key Findings: The amount of products purchased containing caloric sweetener decreased between 2002 and 2018, yet increased for products containing both caloric sweetener and NNS. Regarding specific types of NNS, changes from 2002 to 2018 were noted in the prevalence of households purchasing products containing aspartame (reduced from $60.0 \%$ to $49.4 \% ; P<.05$ ), rebaudioside $A$ (increased from $0.1 \%$ to $25.9 \%$ ), and sucralose (increased from $38.7 \%$ to $71.0 \%)$. Beverages were predominantly responsible for larger volume per capita purchases of products containing only NNS as well as both caloric sweetener and NNS.

trends of NNS use over time. Generalizations of added sweetener categories are also examined to determine whether there have been changes in the prevalence of foods and beverages purchased containing CS, NNS, both CS and NNS, or neither CS nor NNS.

\section{SUBJECTS AND METHODS}

\section{Study Design and Population}

The Nielsen Homescan Consumer Panels (The Nielsen Company) from 2002 and 2018 were used to examine food purchase data for the US population. This panel is an ongoing nationally representative longitudinal survey of between 35,000 and 60,000 households each year and contains information on purchases of packaged food and beverage items at the Universal Product Code (UPC) level (with close to 3 million bar-coded products included over this period). Participating households are given handheld scanners with which they record yearly food purchases from grocery, drug, mass merchandise, and convenience stores. Households also report sociodemographic and household information including gender, income, education, and race or ethnicity of the head of the household. Households included in Homescan are sampled and weighted to be nationally representative. The Homescan data set is used frequently by researchers to examine food consumption and purchasing patterns. ${ }^{22-24}$ The Institution Review Board of University of North Carolina noted these were secondary data with no direct contacts, and the data were exempt from any review.

\section{Linkage of Barcodes Food Products With Nutrition Facts Panel Data}

Each uniquely bar-coded product captured in Homescan was linked with Nutrition Facts Panel data and ingredient information using commercial nutrition databases (ie, Gladson, Label Insight, Product Launch Analytics, and Mintel). These commercial databases contain national brands and private label items at the UPC level, and data are generally updated regularly as new products enter the market. Further details regarding matching these commercial data sets at the UPC level and other methodological facts have been published 
previously. ${ }^{2,25}$ Products were classified as containing NNS in Homescan 2002 and 2018 to examine whether changes have occurred over time. Keyword searches were performed on ingredient lists provided for each UPC purchased by participating households. A detailed list of key terms is available in Figure 1 (available at www.jandonline.org), but in brief, keyword searches were performed for the 4 most commonly consumed NNS (saccharin, aspartame, sucralose, and rebA), ${ }^{19}$ as well as all other known NNS used by US food and beverage manufacturers. The ingredient lists were also examined for CS to determine whether NNS were used alone, or in combination with CS. Estimates of total purchases per year were calculated to estimate total volume purchased per day (milliliters per day for beverages; grams per day for foods) by a household. Then, the total purchases of each household were divided by the number of people in the household to calculate a per capita estimate of purchases. The percent of households purchasing foods and beverages by sweetener type was determined. To define a consumer in a meaningful way and exclude unusual or 1-time purchases, the total purchases per year was divided by predefined portions: 100 for beverages and 50 for foods. For the purpose of this research, a household was considered a consumer in Homescan if purchases totaled at least 52 portions per year, or 1 portion per week.

\section{Food Grouping}

Packaged products in the data are not grouped in a manner that lends themselves to nutrition-related analyses. Our University of North Carolina team of trained members with masters of public health or registered dietitian degrees created a food grouping system and worked through the major beverage and food groupings to create nutritionally meaningful food groups. Figure 2 (available at www. jandonline.org) provides a description of the beverage and food groupings. Based on these groupings, we ranked the top 10 food and beverage groups based on the volume per capita per day of products purchased within these groups containing any nonnutritive sweetener.

\section{Statistical Analysis}

All analyses were performed using SAS v9.4 (2013; SAS Institute) Results are presented overall and by demographic subgroup in both 2002 and 2018. Results are reported for households both with and without children, 3 race-ethnic groups (Hispanic, non-Hispanic white, and non-Hispanic black), 3 income groups ( $<185 \%, 185 \%-350 \%$ and $>350 \%$ of the federal poverty level), and 3 head of household education groups (less than high school, high school diploma, and more than high school). Significant changes between 2002 and 2018 in prevalence of intake were examined using $\chi^{2}$ tests. Results for volume per capita per day are reported mean ( \pm standard error), and differences examined using Student $t$ test. A $P$ value of $<.05$ was considered significant for all reporting.

\section{RESULTS}

In 2002, 39,300 households were included in analysis and 61,101 in 2018 (Table 1). The Homescan data in general had a higher proportion of households without children and nonHispanic whites (Table 2, available at www.jandonline.org).
Table 1. Sociodemographic characteristics of US households ${ }^{a}$ analyzed for purchases of caloric and nonnutritive sweeteners from packaged foods and beverages in 2002 and $2018^{\mathrm{b}}$

\begin{tabular}{|c|c|c|}
\hline Characteristics & 2002 & 2018 \\
\hline No. of households & 39,300 & 61,101 \\
\hline Households without children (\%) & 63.5 & 67.5 \\
\hline $\begin{array}{l}\text { Households with children }<18 \text { y } \\
\text { old (\%) }\end{array}$ & 36.5 & 32.5 \\
\hline \multicolumn{3}{|l|}{ Race or ethnicity (\%) } \\
\hline Hispanic & 9.2 & 13.1 \\
\hline Non-Hispanic white & 76.2 & 68.1 \\
\hline Non-Hispanic black & 11.0 & 11.6 \\
\hline Non-Hispanic other & 3.6 & 7.2 \\
\hline \multicolumn{3}{|l|}{$\begin{array}{l}\text { Household income (\% federal } \\
\text { poverty level) }\end{array}$} \\
\hline$<185$ & 24.5 & 25.3 \\
\hline $185-350$ & 33.2 & 31.9 \\
\hline$>350$ & 42.3 & 42.8 \\
\hline \multicolumn{3}{|l|}{ Head of household education (\%) } \\
\hline Less than high school diploma & 3.4 & 1.9 \\
\hline High school diploma & 26.2 & 25.5 \\
\hline More than high school diploma & 70.4 & 72.6 \\
\hline \multicolumn{3}{|c|}{$\begin{array}{l}\text { aHousehold characteristics based on data reported by Nielsen through its Homescan } \\
\text { Services for the years } 2002 \text { and } 2018 \text { from Nielsen Homescan Household Panel across } \\
\text { the US market, The Nielsen Company, 2019. The conclusions drawn from the Nielsen } \\
\text { data are those of the authors and do not reflect the views of Nielsen. Nielsen is not } \\
\text { responsible for and had no role in, and was not involved in, analyzing and preparing the } \\
\text { results reported herein. } \\
\text { bAll differences between } 2002 \text { and } 2018 \text { are significant at } P<.05 \text {. }\end{array}$} \\
\hline
\end{tabular}

\section{Household Purchases of Products Containing CS}

In $2002,100 \%$ of households purchased products containing CS, which reduced slightly but significantly to $99.9 \%$ in 2018 (Figure 3). The volume of products purchased containing only CS also decreased significantly, from $436.6 \pm 1.6 \mathrm{~g} / \mathrm{d}$ to 362.4 $\pm 1.3 \mathrm{~g} / \mathrm{d}(P<.05$; Figure 4$)$, although the decrease was due to a large decrease in purchases of beverages containing only CS, as food purchases slightly increased over the study period $(227.8 \pm 0.7 \mathrm{~g} / \mathrm{d}$ to $231.0 \pm 0.7 \mathrm{~g} / \mathrm{d}$; Figure 4$)$. All demographic subgroups showed a decrease in volume of foods and beverage purchases overall containing only CS $(P<.05$ for all; Table 2, available at www.jandonline.org). Despite almost $100 \%$ of both households with and without children purchasing products containing CS in 2018, households with children purchased a considerably lower volume of products containing only CS $(259.0 \pm 1.5 \mathrm{~g} / \mathrm{d})$ than households without children $(412.2 \pm 1.7 \mathrm{~g} / \mathrm{d}$; Table 2 , available at www. jandonline.org).

\section{Household Purchases of Products Containing Both CS and NNS}

The opposite trend to purchases containing only CS was seen for household purchases of products containing both CS and 


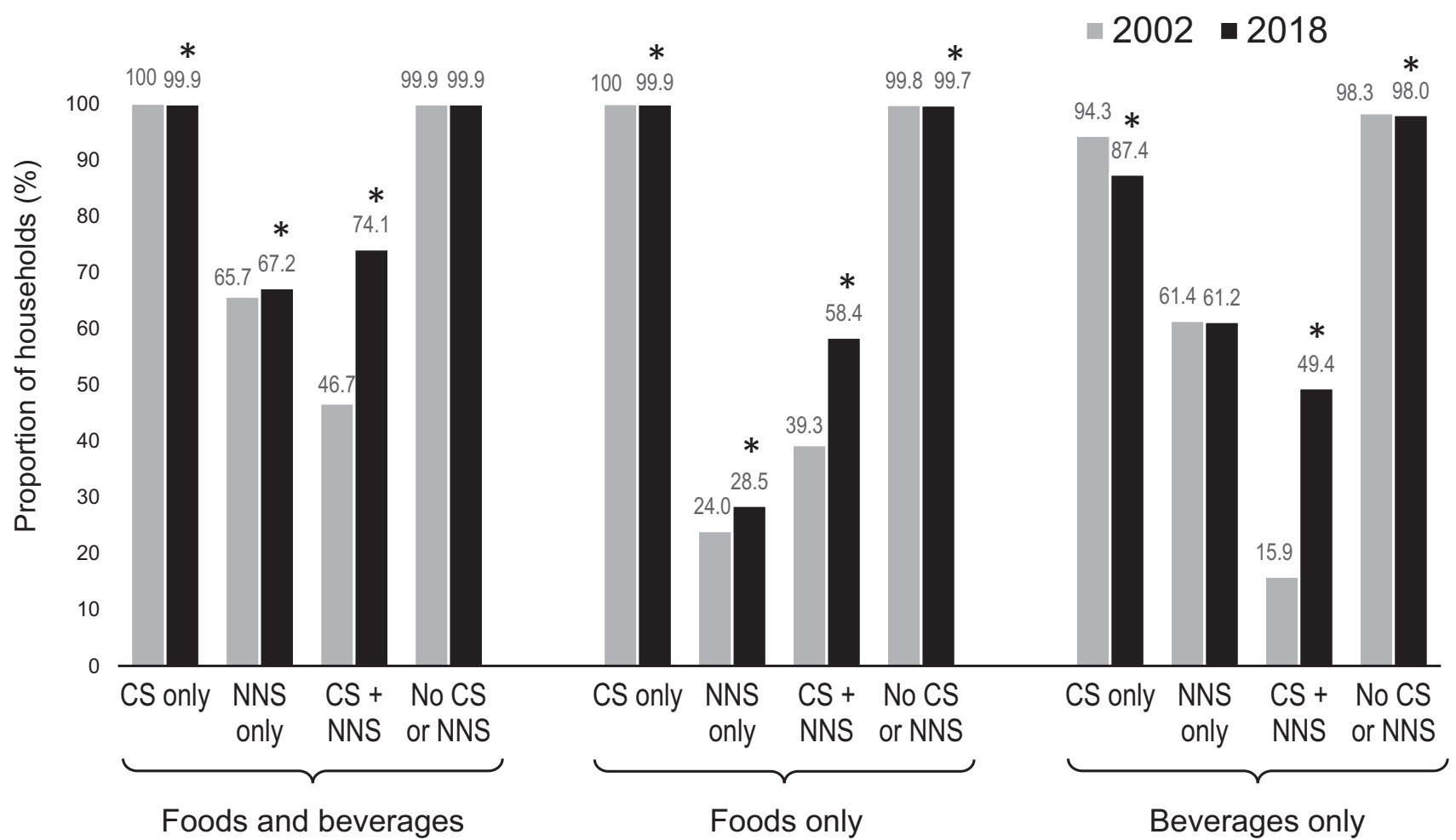

Figure 3. The proportion of households purchasing products containing caloric sweeteners (CS) and nonnutritive sweeteners (NNS), a comparison of 2002 vs 2018. Sample sizes of households were 39,300 in 2002 and 61,101 in 2018. Authors' calculations are based in part on data reported by Nielsen through its Homescan Services for all food categories, including beverages and alcohol for the years 2002 and 2018 from Nielsen Homescan Household Panel across the US market, The Nielsen Company, 2019. The conclusions drawn from the Nielsen data are those of the authors and do not reflect the views of Nielsen. Nielsen is not responsible for and had no role in, and was not involved in, analyzing and preparing the results reported herein. ${ }^{*} P<.05$. CS only: products that contain caloric sweeteners as the only type of sweetener. NNS only: Products that contain nonnutritive sweeteners as the only type of sweetener. CS + NNS: products that contain both caloric and nonnutritive sweeteners. No CS or NNS: products that neither contain caloric sweeteners or nonnutritive sweeteners.

NNS together. The proportion of households purchasing products containing both CS and NNS increased almost 30\% between 2002 and $2018(P<.05$; Figure 3$)$, with the increase driven mainly by beverages, which showed an increase from $15.9 \%$ in 2002 to $49.4 \%$ in 2018 ( $P<.05$; Figure 3$)$. All demographic subgroups showed an increase in both the proportion of households (Table 3, available at www.jandonline. org) and per capita volume purchased of products containing both CS and NNS (Table 2, available at www.jandonline.org). In 2018, non-Hispanic whites purchased the highest volume of food products containing both CS and NNS $(9.6 \mathrm{~g} / \mathrm{d}$ vs 6.4 $\mathrm{g} / \mathrm{d}$ for Hispanics and $5.9 \mathrm{~g} / \mathrm{d}$ for non-Hispanic blacks; Table 4, available at www.jandonline.org), and non-Hispanic blacks purchased the highest volume of beverage products $(32.2 \mathrm{~g} /$ d vs $22.7 \mathrm{~g} / \mathrm{d}$ for Hispanics and $28.4 \mathrm{~g} / \mathrm{d}$ for non-Hispanic whites; Table 5, available at www.jandonline.org). In fact, non-Hispanic black households showed a $42 \%$ increase in the prevalence of households purchasing beverage products containing both CS and NNS between 2002 (21.8\%) and 2018 (56.6\%) (Table 6, available at www.jandonline.org). Interestingly, despite a larger proportion of households with children in 2018 purchasing products containing both CS and NNS (83.6\%) than households without children (68.6\%), households without children had a much higher volume purchased (40.9 $\mathrm{g} / \mathrm{d}$ vs $26.3 \mathrm{~g} / \mathrm{d}$; Table 2, available at www.jandonline.org).

\section{Household Purchases of Products Containing Neither CS nor NNS}

Almost $100 \%$ of households purchased products that contained neither CS nor NNS in both 2002 and 2018 (Figure 3). The volume purchased by households of products containing neither CS nor NNS increased between 2002 and 2018 (355.4 $\mathrm{g} / \mathrm{d}$ to $415.0 \mathrm{~g} / \mathrm{d} ; P<.05$ ) (Figure 4 ), and this was driven by both an increase in food and beverage purchases. Interestingly, in 2002, US households purchased a higher volume of food and beverage products containing only CS $(436.6 \mathrm{~g} / \mathrm{d})$ than neither CS nor NNS ( $355.4 \mathrm{~g} / \mathrm{d}$ ); however, this trend was reversed by 2018 , with $362.4 \mathrm{~g} / \mathrm{d}$ volume purchased of products containing CS only vs $415 \mathrm{~g} / \mathrm{d}$ of products with neither CS nor NNS (Figure 5). In both 2002 and 2018, slightly more US households purchased products containing CS only than products containing neither CS nor NNS (Figure 3).

\section{Household Purchases of Products Containing NNS}

A small but significant increase was observed in household purchases of products containing only NNS (65.7\% in 2002 to $67.2 \%$ in 2018; $P<.05$ ) (Figure 3). The increase was mainly driven by food products, with beverage products showing a smaller increase. However, when examining the volume per capita per day of products purchased that contained only 


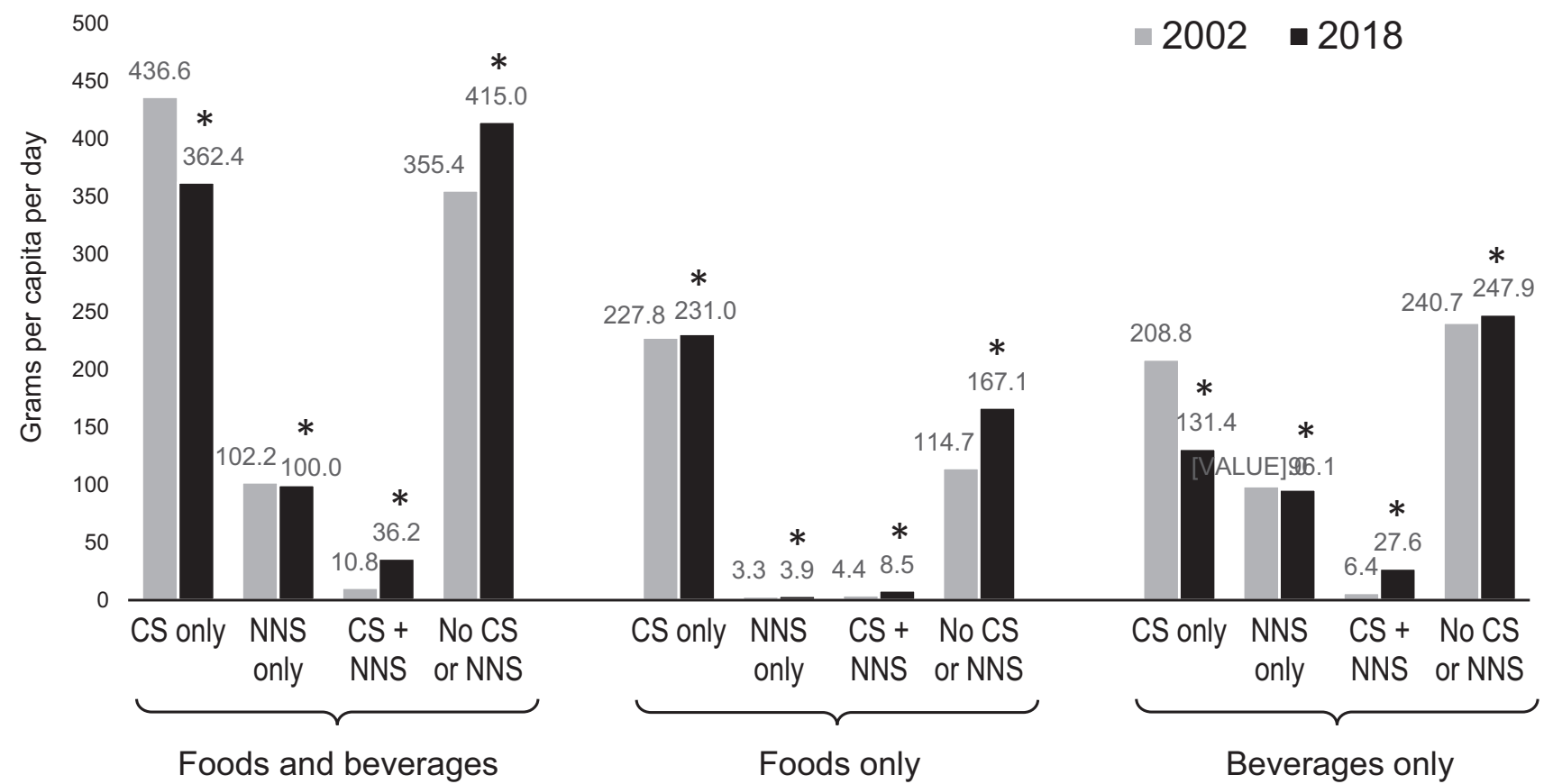

Figure 4. The volume per capita per day of products households purchase containing nonnutritive sweetener (NNS) and caloric sweetener (CS), a comparison of 2002 vs 2018. Sample sizes of households were 39,300 in 2002 and 61,101 in 2018. Authors' calculations are based in part on data reported by Nielsen through its Homescan Services for all food categories, including beverages and alcohol for the years 2002 and 2018 from Nielsen Homescan Household Panel across the US market, The Nielsen Company, 2019. The conclusions drawn from the Nielsen data are those of the authors and do not reflect the views of Nielsen. Nielsen is not responsible for and had no role in, and was not involved in, analyzing and preparing the results reported herein. ${ }^{*} P<$ .05. CS only: products that contain caloric sweeteners as the only type of sweetener. NNS only: products that contain nonnutritive sweeteners as the only type of sweetener. CS + NNS: products that contain both caloric and nonnutritive sweeteners. No CS or NNS: products that neither contain caloric sweeteners or nonnutritive sweeteners.

NNS, a small but significant decrease was observed between 2002 and 2018 (102.2 g/d to $100.0 \mathrm{~g} / \mathrm{d} ; P<.05$ ) (Figure 4 ). Interestingly, non-Hispanic whites purchased almost twice the volume of products containing only NNS compared with Hispanics and non-Hispanic blacks in both survey years (Table 2, available at www.jandonline.org). This finding was mainly due to non-Hispanic whites having higher volume purchases of aspartame (see next section). Households without children purchased more than double the volume of products containing only NNS compared with households with children in $2018(125.9 \pm 1.3 \mathrm{~g} / \mathrm{d}$ vs $46.3 \pm 0.8 \mathrm{~g} / \mathrm{d}$; Table 2, available at www.jandonline.org). In volume terms, these changes overall and by race-ethnic subpopulation group were driven mainly by shifts in beverage purchases

\section{Ranking of Food and Beverage Groups by Household Purchase of Products Containing Any NNS} For applicability, we present the top 10 food and beverage groups ranked based on volume of purchased products containing any NNS within each food or beverage group in Table 7. Most of the products containing NNS are found among beverages. Unsurprisingly, diet and low-calorie ( $\leq 20 \mathrm{kcal} / 100 \mathrm{~mL}$ ) soft and fruit drinks were the major source in 2002 and 2018, though there was a major drop in purchases of these beverages in 2018. This was partly made up by caloric soft and fruit drinks ( $>20 \mathrm{kcal} / 100 \mathrm{~mL}$ ) shifting toward adding NNS in 2018 (moved in ranking from fifth place in 2002 to second place in 2018). In addition, there were important increases in the volume of coffee and teas and water purchased containing NNS. In 2018, purchases of sports and energy drink products containing NNS showed up on the top 10. In the foods categories, there were notable but relatively small increases in the amount of the top 10 food groups with products containing NNS compared with what was seen for beverages. Nonetheless, it shows what food groups are beginning to have growth on NNS use over time and where future increase might be expected.

\section{Changes in Purchases of Specific NNS Types}

Between 2002 and 2018 there was a large change in the prevalence of households purchasing specific NNS types. For example, between 2002 and 2018, the proportion of households purchasing products containing saccharin and aspartame decreased $(1.3 \%$ to $1.1 \%$ for saccharin and $60.0 \%$ to $49.4 \%$ for aspartame; $P<.05$; Figure 5 ), yet a large increase in the proportion of households purchasing reb-A and sucralose was observed ( $0.1 \%$ to $25.9 \%$ for reb-A and $38.7 \%$ to $71.0 \%$ for sucralose; $P<.05$ ) (Figure 5). For all NNS types except for saccharin, products containing each NNS type were more often found among beverage purchases compared with foods. Aspartame had the highest volume per capita purchased of all NNS types, despite showing a significant decrease between 2002 and 2018 (94.7 g/d to $80.0 \mathrm{~g} / \mathrm{d} ; P<.05)$ (Figure 6). A large increase in all other NNS was seen between 2002 to 2018 (40.3 g/d to $91.9 \mathrm{~g} / \mathrm{d} ; P<.05)$, as well as large increases in reb-A (0 g/d in 2002 vs $7.6 \mathrm{~g} / \mathrm{d}$ in 2018) and sucralose (15.4 $\mathrm{g} / \mathrm{d}$ in 2002 vs $49.4 \mathrm{~g} / \mathrm{d}$ in 2018). Saccharin contributed only 


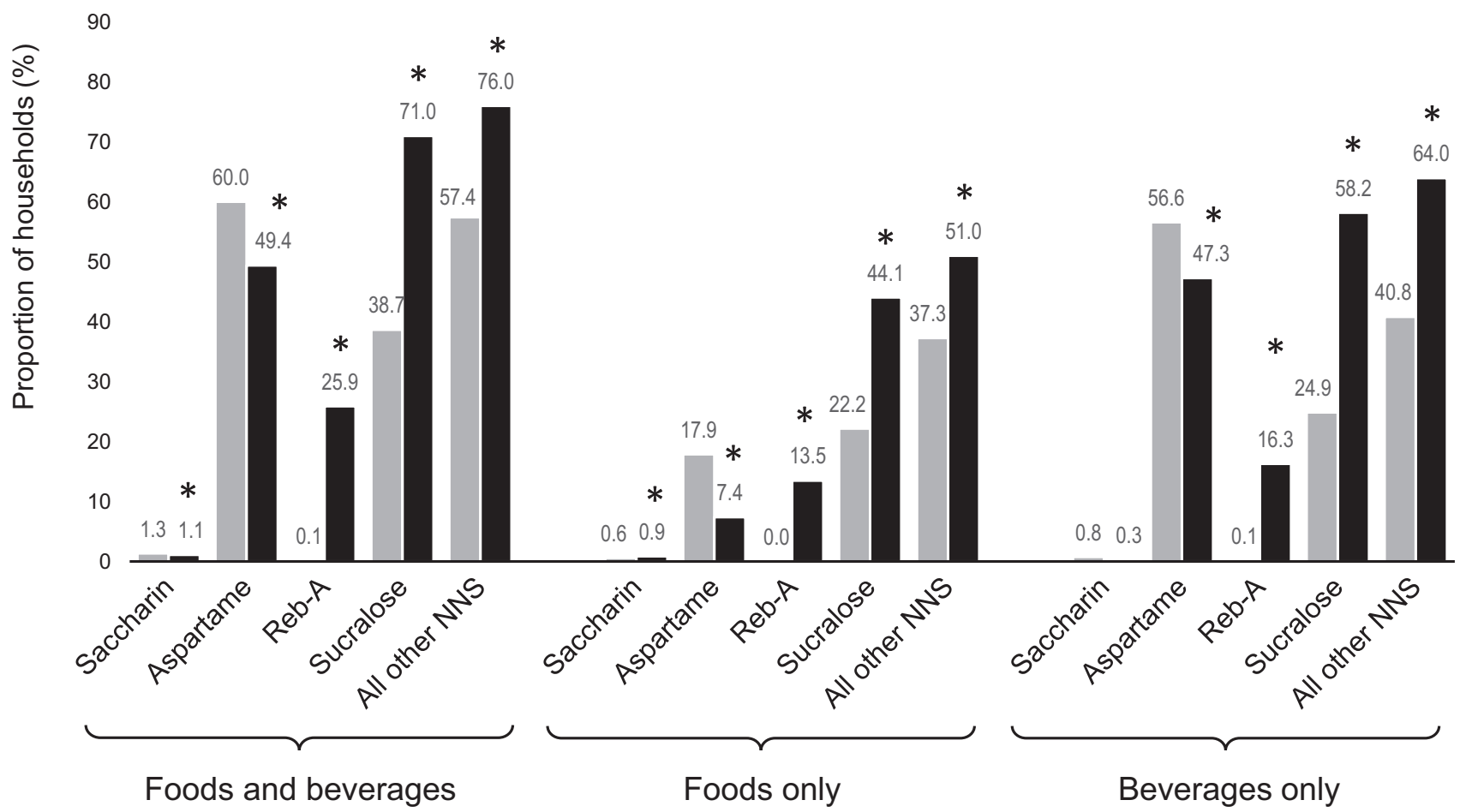

Figure 5. The proportion of households purchasing specific types of nonnutritive sweeteners (NNS), a comparison of 2002 vs 2018. Sample sizes of households were 39,300 in 2002 and 61,101 in 2018. Authors' calculations are based in part on data reported by Nielsen through its Homescan Services for all food categories, including beverages and alcohol for the years 2002 and 2018 from Nielsen Homescan Household Panel across the US market, The Nielsen Company, 2019. The conclusions drawn from the Nielsen data are those of the authors and do not reflect the views of Nielsen. Nielsen is not responsible for and had no role in, and was not involved in, analyzing and preparing the results reported herein. ${ }^{*} P<.05$. Reb-A = rebaudioside $\mathrm{A}$.

$<1 \mathrm{~g} / \mathrm{d}$ in volume purchased per capita (Figure 6). It's also important to note the relative sweetness of each NNS examined compared with sucrose. Figure 7 (available at www.jandonline.org) shows that sucralose has the highest relative sweetness, at $600 \times$ sweeter than sucrose, and reb-A the lowest, with $240 \times$ sweeter than sucrose.

\section{DISCUSSION}

\section{Overall Results}

Using measures of household purchases from nationally representative samples of US households, a large shift was found between 2002 and 2018 in how NNS were being purchased by US consumers. The current study observed, as previous studies have shown, that purchases of products containing CS have decreased in recent years, ${ }^{10,26,27}$ yet the proportion of households purchasing products containing both CS and NNS together has increased by more than $30 \%$. This increase was driven mainly by beverages rather than food, with the volume purchased per capita per day of beverage products with both CS and NNS increasing more than 4 -fold from 2002 to 2018. At the same time, a decrease in volume purchased per capita per day of beverage products containing only NNS was observed. The most recent study examining household purchases of products containing NNS (between 2000 and 2010) found that purchases of products containing NNS increased between 2000 and 2006, and began to decrease between 2006 and 2010. ${ }^{10,28}$ Current results indicate that decline has continued through to 2018. In addition, most studies examining volume purchases or intake of NNS and CS have not also considered how to compare products containing neither CS nor NNS. The current study observed a changing trend, with US households in 2002 purchasing a higher volume of food and beverage products containing only CS vs neither CS nor NNS, with the opposite trend observed in 2018. This highlights the changing nature of both the US food supply and consumer purchasing behavior over the past 16 years.

Although the current study found that foods contributed a larger volume per capita of purchases of products containing only CS (231 g/d vs $131.4 \mathrm{~g} / \mathrm{d}$ in 2018), it was also observed that beverages were predominantly responsible for larger volume per capita purchases of products containing only NNS $(96.1 \mathrm{~g} / \mathrm{d}$ for beverages vs $3.9 \mathrm{~g} / \mathrm{d}$ for foods in 2018) as well as products containing both CS and NNS ( $27.6 \mathrm{~g} / \mathrm{d}$ for beverages vs $8.5 \mathrm{~g} / \mathrm{d}$ for foods in 2018). Volume per capita purchases of beverage products containing only NNS did not change significantly between 2002 and 2018; however, purchases increased significantly for products containing both CS and NNS. This is in line with previous research, which has shown that in both children and adults, consumption of reducedcalorie beverages (eg, reduced-calorie sport drinks) has been increasing while consumption of no-calorie beverages (eg, diet soda) has remained relatively stable., ${ }^{4,9}$ 
Table 7. The top 10 food and beverage groupings for purchased products containing any nonnutritive sweeteners (with or without caloric sweeteners) in US households: a comparison of 2002 vs $2018^{\text {a }}$

\begin{tabular}{|c|c|c|c|}
\hline \multirow[b]{2}{*}{ Group } & \multirow[b]{2}{*}{ Mean $\left(\mathrm{SE}^{\mathrm{b}}\right)$} & \\
\hline & & Group & Mean (SE) \\
\hline \multicolumn{4}{|l|}{ Beverages $^{c}$} \\
\hline $\begin{array}{l}\text { Soft drinks and fruit drinks diet or low calorie } \\
\qquad(\leq 20 \mathrm{kcal} / 100 \mathrm{~g})\end{array}$ & $91.07(1.12)$ & $\begin{array}{l}\text { Soft drinks and fruit drinks diet or low calorie } \\
\qquad(\leq 20 \mathrm{kcal} / 100 \mathrm{~g})\end{array}$ & $58.21(0.74)$ \\
\hline Coffee or tea caloric ( $>20 \mathrm{kcal} / 100 \mathrm{~g}$ ) & $5.83(0.25)$ & $\begin{array}{l}\text { Soft drinks and fruit drinks caloric (>20 kcal/ } \\
\qquad 100 \mathrm{~g} \text { ) }\end{array}$ & $24.41(0.35)$ \\
\hline Water noncaloric $(0 \mathrm{kcal} / 100 \mathrm{~g})$ & $3.02(0.12)$ & Water noncaloric (0 kcal/100 g) & $10.62(0.20)$ \\
\hline $\begin{array}{l}\text { Coffee or tea noncaloric or low calorie ( } \leq 20 \\
\mathrm{kcal} / 100 \mathrm{~g})\end{array}$ & $1.29(0.07)$ & Coffee or tea caloric (>20 kcal/100 g) & $9.56(0.30)$ \\
\hline $\begin{array}{l}\text { Soft drinks and fruit drinks caloric (>20 kcal/ } \\
\qquad 100 \mathrm{~g} \text { ) }\end{array}$ & $1.19(0.04)$ & $\begin{array}{l}\text { Coffee or tea noncaloric or low calorie }(\leq 20 \\
\mathrm{kcal} / 100 \mathrm{~g})\end{array}$ & $6.56(0.18)$ \\
\hline $\begin{array}{l}\text { Cocoa and sweetened milk beverages } \\
\text { powdered }\end{array}$ & $1.16(0.04)$ & $\begin{array}{l}\text { Cocoa and sweetened milk beverages } \\
\text { powdered }\end{array}$ & $3.42(0.16)$ \\
\hline Water diet or low calorie $(\leq 10 \mathrm{kcal} / 100 \mathrm{~g})$ & $0.67(0.05)$ & $\begin{array}{l}\text { Sports drinks diet or low calorie ( } \leq 20 \mathrm{kcal} / \\
100 \mathrm{~g})\end{array}$ & $3.33(0.10)$ \\
\hline $\begin{array}{l}<100 \% \text { fruit juice low calorie }(\leq 20 \mathrm{kcal} / \\
100 \mathrm{~g})\end{array}$ & $0.60(0.03)$ & $\begin{array}{l}<100 \% \text { fruit juice low calorie }(\leq 20 \mathrm{kcal} / \\
100 \mathrm{~g})\end{array}$ & $2.12(0.07)$ \\
\hline $\begin{array}{l}<100 \% \text { vegetable juice low calorie }(\leq 20 \\
\quad \mathrm{kcal} / 100 \mathrm{~g})\end{array}$ & $0.20(0.01)$ & $\begin{array}{l}\text { Energy drinks diet or low calorie }(\leq 20 \mathrm{kcal} / \\
\qquad 100 \mathrm{~g})\end{array}$ & $1.45(0.06)$ \\
\hline$<100 \%$ vegetable juice caloric ( $>20 \mathrm{kcal} / 100 \mathrm{~g}$ ) & $0.18(0.01)$ & $<100 \%$ fruit juice caloric $(>20 \mathrm{kcal} / 100 \mathrm{~g})$ & $1.15(0.03)$ \\
\hline \multicolumn{4}{|l|}{ Food $^{\mathrm{c}}$} \\
\hline Yogurt & $1.82(0.04)$ & Yogurt & $2.47(0.04)$ \\
\hline Dairy-based desserts & $1.31(0.04)$ & Dairy-based desserts & $1.82(0.03)$ \\
\hline Candy and sweet snacks & $1.02(0.03)$ & Dairy products, other & $1.51(0.03)$ \\
\hline Grain-based bars & $0.65(0.01)$ & Candy and sweet snacks & $1.43(0.03)$ \\
\hline Grain-based desserts & $0.49(0.01)$ & Bread and bread products & $1.09(0.02)$ \\
\hline Sweeteners & $0.46(0.01)$ & Sweeteners & $0.60(0.01)$ \\
\hline Salty snacks & $0.36(0.01)$ & Grain-based bars & $0.57(0.01)$ \\
\hline Sauces, dips, and condiments & $0.32(0.01)$ & Grain-based desserts & $0.56(0.01)$ \\
\hline Soups and stews & $0.27(0.01)$ & Fruit & $0.47(0.01)$ \\
\hline Cereal & $0.23(0.01)$ & Sauces, dips, and condiments & $0.41(0.01)$ \\
\hline
\end{tabular}

aSource: Authors' calculations based in part on data reported by Nielsen through its Homescan Services for all food categories, including beverages and alcohol for the years 2002 and 2018 from Nielsen Homescan Household Panel across the US market, The Nielsen Company, 2019. The conclusions drawn from the Nielsen data are those of the authors and do not reflect the views of Nielsen. Nielsen is not responsible for and had no role in, and was not involved in, analyzing and preparing the results reported herein.

${ }^{\mathrm{b}} \mathrm{SE}=$ standard error.

${ }^{c}$ Ranked based on greatest volume per capita per day of purchased products containing any nonnutritive sweetener within each group).

\section{Race-Ethnic Subpopulation Results}

Although similar trends were observed when looking at specific demographic subgroups, non-Hispanic whites were found to purchase almost double the volume of products containing NNS compared with Hispanics and non-Hispanic blacks in both survey years. This supports research into consumption of NNS, which demonstrates that non-Hispanic whites in the United States have a higher prevalence of NNS consumption compared with non-Hispanic black and Hispanic race-ethnic groups. ${ }^{9,10,29}$ Interestingly, though, it was also found that non-Hispanic black households showed a $42 \%$ increase in the proportion of households purchasing beverage products containing both CS and NNS between 2002 and 2018, indicating that purchasing behavior may be changing for this race-ethnic group.

\section{Shifts in the Types of NNS}

A change in the specific types of NNS that are being purchased by US households was also observed. For example, out of the 4 NNS types examined, both prevalence of households 


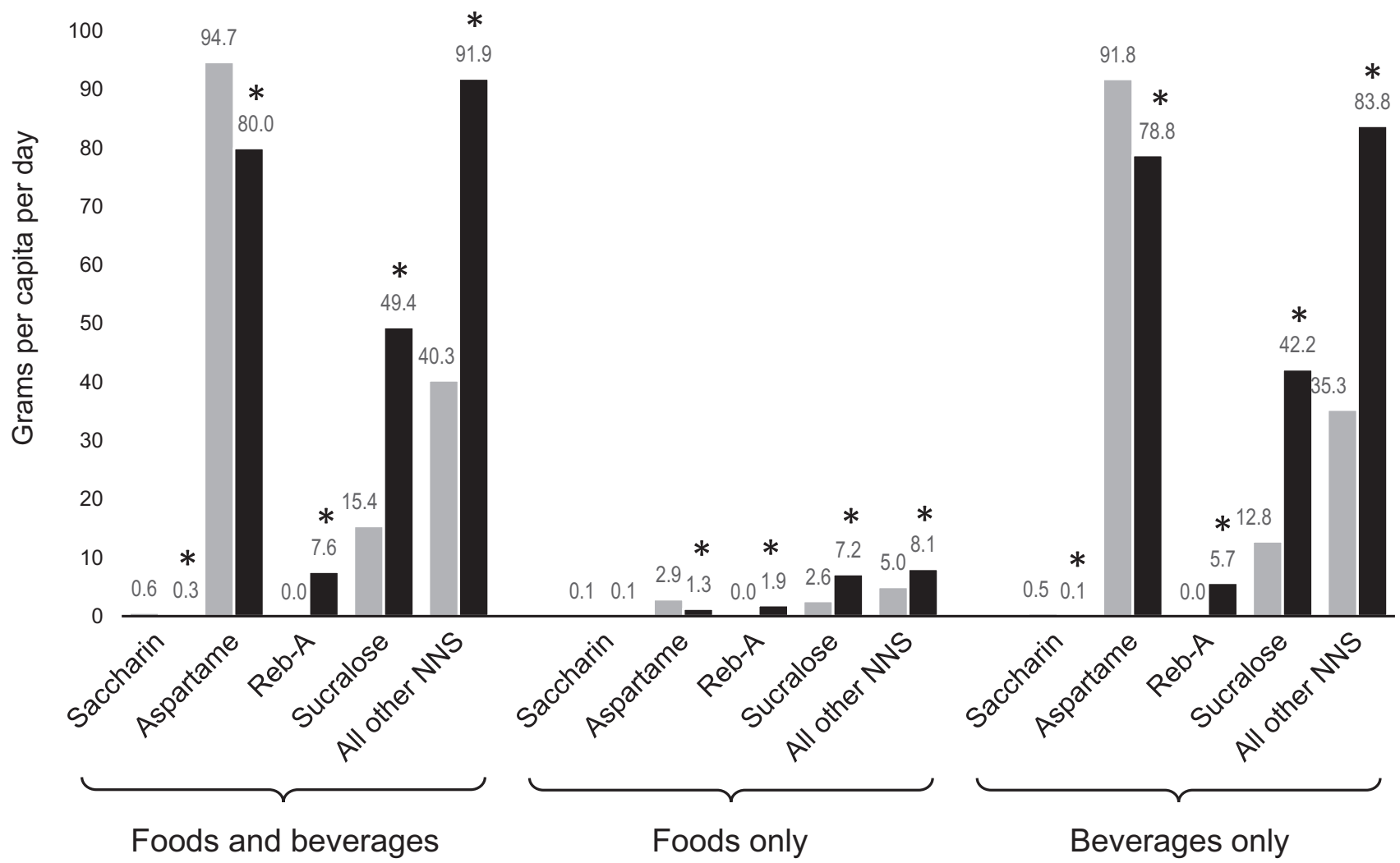

Figure 6. The volume per capita per day of products containing specific types of nonnutritive sweeteners (NNS), a comparison of 2002 vs 2018 . Sample sizes of households were 39,300 in 2002 and 61,101 in 2018. Authors' calculations are based in part on data reported by Nielsen through its Homescan Services for all food categories, including beverages and alcohol for the years 2002 and 2018 from Nielsen Homescan Household Panel across the US market, The Nielsen Company, 2019. The conclusions drawn from the Nielsen data are those of the authors and do not reflect the views of Nielsen. Nielsen is not responsible for and had no role in, and was not involved in, analyzing and preparing the results reported herein. ${ }^{*} P<.05$. Reb-A $=$ rebaudioside $\mathrm{A}$.

purchasing and the volume per capita purchased of saccharin and aspartame decreased, and reb-A and sucralose increased. Reb-A and sucralose are relatively new to the market, and results indicate that these types of sweeteners may in fact be replacing the use of the more traditionally used NNS, such as aspartame. Interestingly, despite saccharin being noted in the literature as one of the most commonly consumed NNS in the United States, ${ }^{19}$ it was found to contribute $<1 \mathrm{~g} / \mathrm{d}$ in terms of purchased volume per capita. With the most recent RCT examining the differential effects of these 4 NNS types showing a negative effect of saccharin on body weight, ${ }^{19}$ it is promising that it is not as widely consumed by US households and that other NNS types currently dominate the US food and beverage supply. That being said, saccharin is found in the common table-top sweetener Sweet'N Low (Cumberland Packing Corporation), and hence a substantial portion of saccharin intake may have been missed in the present study if predominately used outside the home.

Aspartame remains a dominant NNS type purchased (by more than $50 \%$ of households in 2018), although the proportion of households purchasing products containing aspartame decreased by just under $10 \%$ between 2002 and 2018. At the same time, purchases of sucralose increased by more than $30 \%$, driven mainly by beverage products. Reports suggest that sucralose accounts for the majority of the NNS market share in the United States (passing aspartame, which previously represented the majority). ${ }^{30}$ New research conducted on 45 healthy adults found that the consumption of sucralose alongside carbohydrate (eg, in drinks that contain both sucralose and caloric sugars) rapidly impairs glucose metabolism, resulting in decreases in brain sensitivity to sweet taste. ${ }^{31}$

Research suggests that as consumer preferences continue to shift toward more "natural" products, consumption of NNS types such as reb-A will likely increase more rapidly compared with other NNS types. ${ }^{9}$ The present study supports this, showing a large increase in both the proportion of households purchasing, and the volume purchased, of reb-A. In addition to its appeal as a "natural" NNS, reb-A is also touted as being more palatable than other NNS.

\section{Limitations}

Home purchase data such as that found in Homescan do not provide measures of individuals' actual intake; however, these data are useful to characterize the variability in food consumption patterns at the population level. Another challenge of using Homescan is that estimates of per capita purchases might not be comparable with per capita intake 
from dietary intake surveys (eg, National Health and Nutrition Examination Surveys). For example, in a given household all purchases of beverages containing NNS could be consumed by a single member of the household, rather than being consumed by all household members, affecting the per capita estimates made here. Homescan also does not capture food and drinks purchased from fast-food chains and other restaurants, which could have resulted in an underestimate of purchases in the present study.

Another limitation is the low proportion of households without a high school education. Although our weights adjust for this, the Nielsen Homescan data had a smaller sample of lower education households for whom data were collected.

Moreover, in the absence of a requirement that nutrition facts panels contain the amount of each NNS used, it was not possible to determine the actual amounts of each sweetener types present in products. Chile is one of the few if not the only country that has this requirement now.

\section{Strengths and Unique Contributions}

To the knowledge of the authors, this is the first study to examine trends in purchases of US households on specific types of NNS and uses the most currently available household purchase data. Results indicate that a decline in purchases of products containing only CS is happening in tandem with an increase in purchases of products containing both CS and NNS. In addition, beverage purchases appear to be responsible for the majority of this change, and that this has occurred along with a large shift in the specific types of NNS that are being purchased by US households (and therefore being used by the food industry). New NNS types enter the market regularly, and it is important to monitor changes not only in the amount of products containing NNS that US consumers purchase, but also the types of NNS that are present in food and beverage products. A critical gap as NNS prevalence grows will be to add a legal requirement for amounts of NNS by type be added to nutrition facts panel as is done in Chile. Without such information, it would be very challenging to track intake of these mixes of NNS that are becoming more prevalent in our food supply to begin understanding if and what types of effects they may have on population health and in addressing disparities. Efforts to encourage or require food manufacturers to disclose the amounts of the various types of NNS in their products should be undertaken.

\section{References}

1. Popkin BM, Hawkes C. Sweetening of the global diet, particularly beverages: Patterns, trends, and policy responses. Lancet Diabetes Endocrinol. 2016;4(2):174-186.

2. Ng SW, Slining MM, Popkin BM. Use of caloric and noncaloric sweeteners in US consumer packaged foods, 2005-2009. J Acad Nutr Diet. 2012;112(11):1828-1834.

3. Popkin B, Nielsen S. The sweetening of the world's diet. Obes Res. 2003;11(11):1325-1332.

4. Sylvetsky AC, Welsh JA, Brown RJ, Vos MB. Low-calorie sweetener consumption is increasing in the United States. Am J Clin Nutr. 2012;96(3):640-646.

5. World Health Organization. Guideline: Sugar intake for adults and children. https://www.who.int/nutrition/publications/guidelines/ sugars_intake/en/. Published 2015. Accessed January 3, 2020.

6. World Cancer Research Fund International. Curbing global sugar consumption: Effective food policy actions to help promote healthy diets and tackle obesity. http://www.wcrf.org/int/policy/our-policywork/curbing-global-sugar-consumption. Published 2015. Accessed January 3, 2020.

7. Ng SW, Popkin BM. Monitoring foods and nutrients sold and consumed in the United States: Dynamics and challenges. J Acad Nutr Diet. 2012;112(1):41-54.

8. Vyth EL, Steenhuis I, Roodenburg A, Brug J, Seidell JC. Front-of-pack nutrition label stimulates healthier product development: A quantitative analysis. Int J Behav Nutr Phys Act. 2010;7(1):65.

9. Sylvetsky AC, Rother KI. Trends in the consumption of low-calorie sweeteners. Physiol Behav. 2016;164(Pt B):446-450.

10. Piernas C, Ng SW, Popkin B. Trends in purchases and intake of foods and beverages containing caloric and low-calorie sweeteners over the last decade in the United States. Pediatr Obes. 2013;8(4):294-306.

11. Malik VS, Hu FB. Sweeteners and risk of obesity and type 2 diabetes: The role of sugar-sweetened beverages. Curr Diab Rep. 2012;12(2): 195-203.

12. Lutsey PL, Steffen LM, Stevens J. Dietary intake and the development of the metabolic syndrome: The Atherosclerosis Risk in Communities study. Circulation. 2008;117(6):754-761.

13. Duffey KJ, Steffen LM, Van Horn L, Jacobs DR Jr, Popkin BM. Dietary patterns matter: Diet beverages and cardiometabolic risks in the longitudinal Coronary Artery Risk Development in Young Adults (CARDIA) Study. Am J Clin Nutr. 2012;95(4):909-915.

14. Anderson GH, Foreyt J, Sigman-Grant M, Allison DB. The use of lowcalorie sweeteners by adults: Impact on weight management. J Nutr. 2012;142(6):1163S-1169S.

15. de Koning L, Malik VS, Kellogg MD, Rimm EB, Willett WC, Hu FB. Sweetened beverage consumption, incident coronary heart disease and biomarkers of risk in men. Circulation; 2012:1735-1741.

16. de Koning L, Malik VS, Rimm EB, Willett WC, Hu FB. Sugar-sweetened and artificially sweetened beverage consumption and risk of type 2 diabetes in men. Am J Clin Nutr. 2011;93(6):1321-1327.

17. Mattes RD, Popkin BM. Nonnutritive sweetener consumption in humans: Effects on appetite and food intake and their putative mechanisms. Am J Clin Nutr. 2009;89(1):1-14.

18. Tate DF, Turner-McGrievy G, Lyons E, et al. Replacing caloric beverages with water or diet beverages for weight loss in adults: Main results of the Choose Healthy Options Consciously Everyday (CHOICE) randomized clinical trial. Am J Clin Nutr. 2012;95(3):555-563.

19. Higgins KA, Mattes RD. A randomized controlled trial contrasting the effects of 4 low-calorie sweeteners and sucrose on body weight in adults with overweight or obesity. Am J Clin Nutr. 2019;109(5):12881301.

20. Gortmaker SL, Story M, Powell LM, Krebs-Smith SM. Building infrastructure to document the U.S. food stream. Am J Prev Med. 2013;44(2):192-193.

21. Poti JM, Mendez MA, Ng SW, Popkin BM. Is the degree of food processing and convenience linked with the nutritional quality of foods purchased by US households? Am J Clin Nutr. 2015;99(1):162-171.

22. Poti JM, Dunford EK, Popkin BM. Sodium reduction in US households' packaged food and beverage purchases, 2000 to 2014. JAMA Intern Med. 2017;177(7):986-994.

23. Grummon AH, Taillie LS. Supplemental Nutrition Assistance Program participation and racial/ethnic disparities in food and beverage purchases. Public Health Nutr. 2018;21(18):3377-3385.

24. Poti JM, Mendez MA, Ng SW, Popkin BM. Highly processed and ready-to-eat packaged food and beverage purchases differ by race/ ethnicity among US households. J Nutrition. 2016;146(9):1722-1730.

25. Slining MM, Ng SW, Popkin BM. Food companies' caloriereduction pledges to improve U.S. diet. Am J Prev Med. 2013;44(2):174-184.

26. Marriott BP, Hunt KJ, Malek AM, Newman JC. Trends in intake of energy and total sugar from sugar-sweetened beverages in the United States among children and adults, NHANES 2003-2016. Nutrients. 2019;11(9).

27. Kit BK, Fakhouri TH, Park S, Nielsen SJ, Ogden CL. Trends in sugarsweetened beverage consumption among youth and adults in the United States: 1999-2010. Am J Clin Nutr. 2013;98(1):180-188.

28. Ng SW, Slining MM, Popkin BM. Turning point for US diets? Recessionary effects or behavioral shifts in foods purchased and consumed. Am J Clin Nutr. 2014;99(3):609-616. 
29. Drewnowski A, Rehm CD. Socio-demographic correlates and trends in low-calorie sweetener use among adults in the United States from 1999 to 2008. Eur J Clin Nutr. 2015;69(9):1035-1041.

30. BCC Research. The market for high-intensity sweeteners is expected to reach nearly $\$ 1.9$ billion in 2017. https://www.bccresearch.com/ pressroom/fod/market-high-intensity-sweeteners-expected-reach- nearly-\$1.9-billion-2017. Published 2013. Accessed January 3, 2020.

31. IHS Markit. Chemical economics handbook. High-intensity sweeteners. https://ihsmarkit.com/products/high-intensity-sweetenerschemical-economics-handbook.html. Published 2017. Accessed January 3, 2020.

\section{AUTHOR INFORMATION}

E. K. Dunford is a research fellow, Food Policy Division, The George Institute for Global Health, University of New South Wales, Sydney, Australia. D. R. Miles is a research programming unit director, Department of Nutrition, Gillings Global School of Public Health, and S. W. Ng is a research assistant professor and B. Popkin is a W. R. Kenan Jr distinguished professor, Carolina Population Center, all at the University of North Carolina at Chapel Hill, Chapel Hill.

Address correspondence to: Barry Popkin, PhD, Carolina Population Center CB \# 8120 Carolina Square, University of North Carolina at Chapel Hill, Chapel Hill, NC 27516-3997. E-mail: popkin@unc.edu

\section{STATEMENT OF POTENTIAL CONFLICT OF INTEREST}

No potential conflict of interest was reported by the authors.

\section{FUNDING/SUPPORT}

Funding for this work comes primarily from Arnold Ventures with additional support from the Carolina Population Center National Institutes of Health grant P2C HD050924.

\section{AUTHOR CONTRIBUTIONS}

E. K. Dunford, D. R. Miles, S. W. Ng, and B. Popkin designed and conducted this research. D. R. Miles analyzed data. E. K. Dunford drafted the paper. E. K. Dunford, S. W. Ng, and B. Popkin had joint primary responsibility for final content. 


\begin{tabular}{|c|c|c|c|c|}
\hline Saccharin & Aspartame & Reb-A & Sucralose & All other NNS \\
\hline Necta Sweet & Aspartame & Enliten & Kaltame & Acesulfame \\
\hline Saccharin & InstaSweet & Reb-a & Splenda & Advantame \\
\hline Sweet'N Low & NatraTaste & Rebaudioside A & Sucralose & Alitame \\
\hline \multirow[t]{30}{*}{ Sugar Twin } & & Rebiana & Trichlorogalactosucrose & Brazzein \\
\hline & & Stevia & Altern & Curculin \\
\hline & & Sugarleaf & & Cweet \\
\hline & & Candyleaf & & Cyclamate \\
\hline & & Candy leaf & & Cyclamic acid \\
\hline & & SweetLeaf & & Erythritol \\
\hline & & Purevia & & Galactitol \\
\hline & & $\begin{array}{l}\text { Steviol } \\
\text { glycoside }\end{array}$ & & Glucitol \\
\hline & & & & Hydrogenated isomaltulose \\
\hline & & & & Isomalt \\
\hline & & & & Lactitol \\
\hline & & & & Lumbah \\
\hline & & & & Luo han guo \\
\hline & & & & Mabinlin \\
\hline & & & & Maltitol \\
\hline & & & & Mannitol \\
\hline & & & & Monatin \\
\hline & & & & Monellin \\
\hline & & & & Monk fruit extract \\
\hline & & & & Monk fruit \\
\hline & & & & $\begin{array}{l}\text { Neohesperidin } \\
\text { dihydrochalcone }\end{array}$ \\
\hline & & & & Osladin \\
\hline & & & & Oubli \\
\hline & & & & Pentadin \\
\hline & & & & Polyglycitol \\
\hline & & & & Sorbitol \\
\hline & & & & Sunett \\
\hline & & & & Sweet One \\
\hline & & & & Twinsweet \\
\hline & & & & Truvia \\
\hline
\end{tabular}

Figure 1. Keywords used to search for each nonnutritive sweetener (NNS) category. ${ }^{a}$ Reb-A = rebaudioside A. 


\begin{tabular}{|l|c|c|c|c|}
\hline Saccharin & Aspartame & Reb-A & Sucralose & All other NNS \\
\hline & & & & Thaumatin \\
\hline & & & Xylitol \\
\hline & & & \\
\hline
\end{tabular}

Figure 1. (continued) Keywords used to search for each nonnutritive sweetener (NNS) category. ${ }^{a}$ Reb-A = rebaudioside A. 


\begin{tabular}{|c|c|}
\hline Group Name & Group Description \\
\hline \multicolumn{2}{|l|}{ Beverages } \\
\hline Water, noncaloric & $\begin{array}{l}\text { Includes water with } 0 \mathrm{kcal} / 100 \mathrm{~g} \text { (tap or bottled; carbonated or noncarbonated). Examples include } \\
\text { tap water; plain bottled water; plain club soda, sparkling water, seltzer water, or sparkling mineral } \\
\text { water; carbonated water sweetened with noncaloric sweetener. }\end{array}$ \\
\hline $\begin{array}{l}\text { Water, diet or low } \\
\text { calorie }\end{array}$ & Includes bottled flavored waters (carbonated or noncarbonated) with $\leq 10 \mathrm{kcal} / 100 \mathrm{~g}$. \\
\hline Water, caloric & $\begin{array}{l}\text { Includes bottled flavored waters (carbonated or noncarbonated) with }>10 \mathrm{kcal} / 100 \mathrm{~g} \text {. Examples } \\
\text { include vitamin water; tonic water. }\end{array}$ \\
\hline $\begin{array}{l}\text { Coffee and tea, } \\
\text { noncaloric and } \\
\text { diet or low calorie }\end{array}$ & $\begin{array}{l}\text { Includes coffee and tea with } \leq 20 \mathrm{kcal} / 100 \mathrm{~g} \text { (combined with milk, cream, or sweeteners). Examples } \\
\text { include regular or decaf coffee from ground; regular or decaf coffee from instant (unsweetened or } \\
\text { presweetened with LCS } \text { or prelightened); tea brewed from leaves; herbal tea; instant tea } \\
\text { (unsweetened or presweetened with LCS); tea presweetened with LCS. }\end{array}$ \\
\hline $\begin{array}{l}\text { Coffee and tea, } \\
\text { caloric }\end{array}$ & $\begin{array}{l}\text { Includes coffee and tea with }>20 \mathrm{kcal} / 100 \mathrm{~g} \text { (combined with milk, cream, or sweeteners) and coffee } \\
\text { beverages. Examples include presweetened tea; presweetened instant tea; regular or decaf coffee } \\
\text { from ground or instant with caloric sweetener or milk added by the consumer; presweetened or } \\
\text { prelightened coffee; coffee latte; cappuccino; mocha; blended coffee beverages. }\end{array}$ \\
\hline $\begin{array}{l}\mathrm{SSB}^{\mathrm{b}} \text {, diet or low } \\
\text { calorie }\end{array}$ & $\begin{array}{l}\text { Includes soft drinks and fruit drinks with } \leq 20 \mathrm{kcal} / 100 \mathrm{~g} \text {. Examples include cola-type, fruit-flavored, } \\
\text { or pepper-type sugar-free soft drinks; low-calorie fruit-flavored drinks from powdered mix; low- } \\
\text { calorie fruit juice drinks or juice cocktail; low-calorie fruit-flavored drinks; sugar-free root beer, } \\
\text { cream soda, or ginger ale; sugar-free fruit- or vanilla-flavored cola; low-calorie lemonade; low- } \\
\text { calorie fruit and vegetable juice drink; low-calorie mixes for mixed alcoholic beverages (margaritas, } \\
\text { daiquiris; liquid, powder, or frozen). Fruit drinks include beverages primarily composed of sugar or } \\
\text { sweetener (as first or second ingredients) with fruit juice or fruit juice concentrate as a lesser } \\
\text { ingredient. Fruit-flavored drinks contain fruit flavors but no fruit juice or fruit juice concentrate. }\end{array}$ \\
\hline SSB, caloric & $\begin{array}{l}\text { Includes soft drinks and fruit drinks with }>20 \mathrm{kcal} / 100 \mathrm{~g} \text {. Examples include cola-type, fruit-flavored, } \\
\text { or pepper-type soft drinks; fruit-flavored drinks from powdered mix; fruit juice drinks or juice } \\
\text { cocktail; fruit-flavored drinks; root beer, cream soda, or ginger ale; reduced-sugar fruit juice drinks; } \\
\text { fruit- or vanilla-flavored cola; fruit and vegetable juice drinks; lemonade; orangeade; light orange } \\
\text { juice; grapeade; limeade; carbonated juice drinks; fruit punch; fruit-flavored frozen drink (slushie); } \\
\text { mixes for mixed alcoholic beverages (margaritas, daiquiris; liquid, powder, or frozen). Fruit drinks } \\
\text { include beverages primarily composed of sugar or sweetener (as first or second ingredients) with } \\
\text { fruit juice or fruit juice concentrate as a lesser ingredient. Fruit-flavored drinks contain fruit flavors } \\
\text { but no fruit juice or fruit juice concentrate. }\end{array}$ \\
\hline $\begin{array}{l}<100 \% \text { fruit juice, } \\
\text { low calorie }\end{array}$ & $\begin{array}{l}\text { Fruit juice, }<100 \% \text { with } \leq 20 \mathrm{kcal} / 100 \mathrm{~g} \text {, not from concentrate or from concentrate (orange, } \\
\text { grapefruit, apple, grape, pineapple, prune juices; juice blends; coconut water); sweetened juice } \\
\text { (sweetened cranberry juice, fruit nectars, and juice blends); frozen fruit juice concentrate. }\end{array}$ \\
\hline $\begin{array}{l}<100 \% \text { vegetable } \\
\text { juice, low calorie }\end{array}$ & $\begin{array}{l}\text { Vegetable juice, }<100 \% \text { with } \leq 20 \mathrm{kcal} / 100 \mathrm{~g} \text {, not from concentrate or from concentrate (tomato } \\
\text { juice, tomato or vegetable juice blends, carrot juice); sweetened vegetable and fruit juice blends. }\end{array}$ \\
\hline $\begin{array}{l}\text { Milk-sweetened or } \\
\text { flavoured }\end{array}$ & $\begin{array}{l}\text { Fresh or shelf-stable chocolate, strawberry, or flavored milk; milk drinks (eg, containing oil, thickeners, } \\
\text { or mostly water, such as milk shake drinks). }\end{array}$ \\
\hline $\begin{array}{l}\text { Cocoa and } \\
\text { sweetened milk } \\
\text { beverages- } \\
\text { powdered }\end{array}$ & $\begin{array}{l}\text { Hot chocolate or cocoa mix; powder for flavored milk; instant breakfast; coffee beverages (coffee } \\
\text { with milk or creamer, such as latte, mocha, or cappuccino instant mixes), tea drinks (tea with milk } \\
\text { or creamer, such as chai tea latte, instant mixes). }\end{array}$ \\
\hline
\end{tabular}

Figure 2. Major food subcategories of foods and beverages in the major food and beverage group table. 


\begin{tabular}{|c|c|}
\hline Group Name & Group Description \\
\hline $\begin{array}{l}\text { Sports drinks, diet or } \\
\text { low calorie }\end{array}$ & $\begin{array}{l}\text { Includes sports drinks and fluid replacement beverages with } \leq 20 \mathrm{kcal} / 100 \mathrm{~g} \text {. Examples include low- } \\
\text { calorie fruit-flavored sports drinks or thirst quenchers. }\end{array}$ \\
\hline $\begin{array}{l}\text { Energy drinks, diet } \\
\text { or low calorie }\end{array}$ & Includes energy drinks with $\leq 20 \mathrm{kcal} / 100 \mathrm{~g}$. \\
\hline \multicolumn{2}{|l|}{ Food } \\
\hline Yogurt & Yogurt (plain or sweetened or flavored); yogurt drinks, shakes, or smoothies; kefir. \\
\hline Dairy-based desserts & $\begin{array}{l}\text { Ice cream; sherbet; ice milk; frozen yogurt; ice cream bars, cones, sandwiches; pudding; cheesecake; } \\
\text { tiramisu; mousse. }\end{array}$ \\
\hline Dairy products & $\begin{array}{l}\text { Sour cream, cream, half-and-half, whipping cream, creamer (liquid or powdered), whipped cream, } \\
\text { whipped topping, evaporated milk, sweetened condensed milk. }\end{array}$ \\
\hline $\begin{array}{l}\text { Candy and sweet } \\
\text { snacks }\end{array}$ & $\begin{array}{l}\text { Candy, chocolate, candy bars, marshmallows, fudge, toffee, baking chocolate, morsels, sprinkles, } \\
\text { gum, mints, candy-making kits; fruit snacks, fruit leather, fruit bars, maraschino cherries, caramel } \\
\text { apples, candied apples; popsicles, sorbet, ices, gelatin; fruit salads with gelatin, ambrosia; fried } \\
\text { apple or banana chips, chocolate- or yogurt-covered fruit, chocolate- or yogurt-covered nuts or } \\
\text { seeds, candy-coated nuts or seeds. }\end{array}$ \\
\hline Grain-based bars & Granola bars, cereal bars, snack bars, crispy rice bars, meal replacement bars. \\
\hline Grain-based desserts & $\begin{array}{l}\text { Refrigerated ready-to-bake cookies, brownies, sweet rolls, Danish, pie crusts; frozen cake, pie, } \\
\text { cobbler, turnovers, coffee cake, honey buns, toaster pastries, brownies, cookies, doughnuts, cream } \\
\text { puffs, éclairs, tarts, muffins, pastry shells, pie crusts; shelf-stable ready-to-eat cookies, brownies, } \\
\text { snack cakes, cupcakes, oatmeal cream pies, single-serve fruit snack pies, graham crackers, animal } \\
\text { crackers, doughnuts, coffee cake, Danish, sweet rolls, honey buns, toaster pastries, scones, muffins, } \\
\text { cake, turnovers, éclairs, tarts, croissants, puff pastry, prepared pie crusts, pastry shells, tart shells, ice } \\
\text { cream cones or bowls; baking mixes for cake or cupcakes, brownies, cookies, muffins, coffee cake, } \\
\text { gingerbread, dessert bars, cobblers or crisps, no-bake pies, pie crust, scones, shortcake. }\end{array}$ \\
\hline $\begin{array}{l}\text { Bread and bread } \\
\text { products }\end{array}$ & $\begin{array}{l}\text { Fresh bread, cinnamon or raisin bread, breadsticks, pita bread, rolls, hot dog or hamburger buns, } \\
\text { sandwich rolls, bagels, English muffins, pizza crusts; refrigerated ready-to-bake rolls, breadsticks, } \\
\text { garlic bread, pizza crusts, dough; frozen dough, bread, breadsticks, rolls, bagels, garlic bread, } \\
\text { English muffins, hot dog or hamburger buns, pizza crusts; shelf-stable bread crumbs, canned } \\
\text { brown bread, croutons, grain-based imitation bacon bits; mixes for bread, rolls, or pizza crust; } \\
\text { breading or batter mixes. }\end{array}$ \\
\hline $\begin{array}{l}\text { Sugars, sweeteners, } \\
\text { syrups, and } \\
\text { toppings }\end{array}$ & $\begin{array}{l}\text { Granulated sugar, brown sugar, powdered sugar; honey, molasses, sorghum syrup, corn syrup, } \\
\text { flavored granulated sugar, nonnutritive sweeteners, agave nectar; jam, preserves, marmalade, fruit } \\
\text { or pumpkin butter, jelly, lemon curd; pancake syrup, pure maple syrup, flavored syrups for coffee } \\
\text { drinks or Italian soda, fruit syrups, chocolate or fruit-flavored dessert or milk syrup, icing, dessert } \\
\text { topping (eg, caramel, butterscotch, hot fudge, strawberry topping, marshmallow cream), hazelnut } \\
\text { spread, cake decorations, pastry filling, marzipan. }\end{array}$ \\
\hline Salty snacks & $\begin{array}{l}\text { Potato chips, potato crisps, sweet potato chips, corn nuts, crispy green peas; crackers, snack crackers, } \\
\text { corn chips, pretzels, tortilla chips, cheese-flavored tortilla chips, cheese puffs, pita chips, popcorn } \\
\text { (unpopped kernels, microwaveable, or prepopped), sandwich crackers, rice cakes, snack mixes with } \\
\text { crackers; soy nuts, chocolate- or yogurt-covered soynuts; pork rinds. }\end{array}$ \\
\hline
\end{tabular}

Figure 2. (continued) Major food subcategories of foods and beverages in the major food and beverage group table. 


\begin{tabular}{|c|c|}
\hline Group Name & Group Description \\
\hline $\begin{array}{l}\text { Sauces, condiments, } \\
\text { and dips }\end{array}$ & $\begin{array}{l}\text { Ready-to-heat shelf-stable or refrigerated tomato-based pasta sauces or spaghetti sauces (plain, } \\
\text { marinara, mushroom, meat, Bolognese, } 4 \text { cheese); Alfredo sauce, cheese sauce, prepared gravy, } \\
\text { pizza sauce, sloppy joe sauce, enchilada sauce, curry sauce, simmer sauce, white or red clam sauce, } \\
\text { chili sauce, pesto sauce, béarnaise sauce, butter sauce, cooking wine, teriyaki sauce, marinades, } \\
\text { glazes, stir fry sauce, and dry mixes for gravy; mayonnaise, sandwich spreads; salad dressing (shelf- } \\
\text { stable and refrigerated); coleslaw dressing; ketchup, barbecue sauce; soy sauce, oyster sauce, fish } \\
\text { sauce, hoisin sauce, tamari sauce, ponzu sauce; mustard, tartar sauce, cocktail sauce, hot sauce, } \\
\text { tabasco sauce, vinegar, Worcestershire sauce, taco sauce, picante sauce, sweet and sour sauce, } \\
\text { duck sauce, steak sauce, wing sauce, honey mustard sauce, horseradish, pickle relish, other } \\
\text { vegetable relishes, fruit relish, fruit chutney, vegetable-based spreads and tapenades (olive } \\
\text { tapenade, artichoke tapenade, eggplant tapenade or spread), yeast extract; salsa; guacamole; } \\
\text { ready-to-heat cheese dip or salsa con queso; dairy-based chip or vegetable dip (eg, French onion, } \\
\text { ranch, dill); black bean dip, hummus; spinach dip; crab dip, smoked salmon dip; caramel dip; } \\
\text { chocolate dipping sauce or fondue. }\end{array}$ \\
\hline Soups and stews & $\begin{array}{l}\text { Noodle- or rice-based soups (eg, chicken noodle, chicken and rice, ramen noodles); meat-based } \\
\text { soups (eg, meat-based chili, beef stew, beef vegetable soup); vegetable-based soups (eg, } \\
\text { vegetable soup, tomato soup, French onion soup, cream of mushroom, gazpacho); starchy- } \\
\text { vegetable based soups (eg, potato soup, corn chowder, cream of potato); legume-based soups (eg, } \\
\text { split pea, lentil, black bean, bean-based chili); dairy-based soups (eg, cheddar cheese soup, broccoli } \\
\text { cheese, clam chowder, cream of mushroom); broth, stock, bouillon. }\end{array}$ \\
\hline Cereal & $\begin{array}{l}\text { Ready-to-eat cereal including corn flakes, frosted flakes, raisin bran, frosted shredded wheat, toasted } \\
\text { oat cereal, crispy rice, chocolate flavored cereals, bran flakes, fruit-flavored cereals, puffed rice, } \\
\text { shredded wheat, granola; hot cereals including oatmeal, grits, cream of wheat, cream of rice. }\end{array}$ \\
\hline Fruit & $\begin{array}{l}\text { Fresh or refrigerated bags or containers of fresh apples, oranges, lemons, cherries, figs, grapes, } \\
\text { berries, apricots, avocado, coconuts; refrigerated apple slices or fresh cut fruit (eg, melon, } \\
\text { pineapple, or fruit mixtures), apple slices with caramel or peanut butter dip, packaged fruit with } \\
\text { yogurt dip, packaged refrigerated sweetened cut fruit in juice or syrup (eg, peaches, pineapple, } \\
\text { grapefruit, mandarin oranges, and fruit mixtures); frozen strawberries, raspberries, blueberries, } \\
\text { blackberries, peaches, pineapple, melon, mango, cherries, cranberries, and fruit mixtures } \\
\text { (unsweetened or sweetened); dried raisins, cranberries, dates, plums (ie, prunes), apricots, figs, } \\
\text { mango, pineapple, cherries, blueberries, apples, coconut, and mixtures of dried fruit; dried or } \\
\text { baked apple chips (unsweetened or sweetened); canned or shelf-stable peaches, pears, pineapple, } \\
\text { mandarin oranges, apricots, grapefruit, cherries, plums, other fruits, fruit cocktail, fruit mixtures, } \\
\text { fruit salads (in heavy syrup, light syrup, or juice, or water); canned coconut; canned or shelf-stable } \\
\text { apple sauce, cranberry sauce, or pickled fruit. }\end{array}$ \\
\hline
\end{tabular}

Figure 2. (continued) Major food subcategories of foods and beverages in the major food and beverage group table. 
Table 2. Volume per capita per day of products containing NNS ${ }^{\mathrm{a}}$ and $\mathrm{CS}^{\mathrm{b}}$ by demographic subgroup of US households: a comparison of 2002 vs 2018 foods and beverages combined

\begin{tabular}{|c|c|c|c|c|c|c|c|c|}
\hline \multirow[b]{2}{*}{ Beverage Categories } & \multicolumn{2}{|c|}{ CS Only } & \multicolumn{2}{|c|}{ NNS Only } & \multicolumn{2}{|c|}{ CS and NNS ${ }^{f}$} & \multicolumn{2}{|c|}{ No CS or $\mathrm{NNS}^{\mathrm{g}}$} \\
\hline & 2002 & 2018 & 2002 & 2018 & 2002 & 2018 & 2002 & 2018 \\
\hline Household with children $<18$ y old & $375.7(2.2)$ & $259.0(1.5)$ & $51.2(1.0)$ & $46.3(0.8)$ & $8.3(0.2)$ & $26.3(0.4)$ & $261.6(1.7)$ & $282.0(1.6)$ \\
\hline Household without children & $471.6(2.1)$ & $412.2(1.7)$ & $131.7(1.7)$ & $125.9(1.3)$ & $12.2(0.2)$ & $40.9(0.4)$ & $409.5(2.0)$ & $479.1(1.9)$ \\
\hline \multicolumn{9}{|l|}{ Head of household education } \\
\hline Less than high school & $510.6(13.9)$ & $448.4(16.0)$ & $90.2(7.2)$ & $90.1(9.5)$ & $9.8(1.2)$ & $41.5(2.9)$ & $417.9(17.8)$ & $487.7(19.8)$ \\
\hline High school diploma & $480.0(3.7)$ & $447.6(3.7)$ & $101.3(2.4)$ & $114.2(2.6)$ & $11.4(0.4)$ & $43.4(0.9)$ & $377.9(3.2)$ & $472.6(4.1)$ \\
\hline More than high school & $416.8(1.8)$ & $330.2(1.3)$ & $103.2(1.4)$ & $95.3(1.0)$ & $10.6(0.2)$ & $33.5(0.3)$ & $344.0(1.6)$ & $392.9(1.5)$ \\
\hline \multicolumn{9}{|c|}{ Household income ( $\%$ federal poverty level) } \\
\hline$<185$ & $446.2(4.3)$ & $415.7(3.5)$ & $79.3(2.5)$ & $94.7(2.4)$ & $9.3(0.4)$ & $40.7(0.8)$ & $331.8(3.4)$ & $422.9(3.7)$ \\
\hline $185-350$ & $451.0(2.9)$ & $357.0(2.0)$ & $94.3(1.8)$ & $87.4(1.4)$ & $10.6(0.3)$ & $35.2(0.5)$ & $366.3(2.8)$ & $399.0(2.4)$ \\
\hline$>350$ & $419.5(2.1)$ & $334.8(1.8)$ & $121.8(1.9)$ & $112.6(1.5)$ & $11.7(0.2)$ & $34.2(0.5)$ & $360.6(2.0)$ & $422.3(2.1)$ \\
\hline \multicolumn{9}{|l|}{ Race or ethnicity } \\
\hline Hispanic & $381.0(5.9)$ & $284.2(3.9)$ & $57.1(2.6)$ & $56.5(2.1)$ & $9.8(0.5)$ & $29.2(0.9)$ & $289.5(4.9)$ & $355.7(4.9)$ \\
\hline Non-Hispanic white & $448.0(1.8)$ & $385.2(1.5)$ & $117.7(1.4)$ & $120.9(1.2)$ & $11.2(0.2)$ & $38.1(0.4)$ & $376.1(1.7)$ & $438.0(1.7)$ \\
\hline Non-Hispanic black & $423.9(5.5)$ & $365.5(4.3)$ & $46.3(1.9)$ & $57.4(1.9)$ & $9.4(0.4)$ & $38.1(0.8)$ & $287.8(3.9)$ & $389.6(4.7)$ \\
\hline Total sample & $436.6(1.6)$ & $362.4(1.3)$ & $102.2(1.2)$ & $100.0(1.0)$ & $10.8(0.2)$ & $36.2(0.3)$ & $355.4(1.5)$ & $415.0(1.5)$ \\
\hline
\end{tabular}

${ }^{a} \mathrm{NNS}=$ nonnutritive sweetener.

${ }^{\mathrm{C}} \mathrm{CS}=$ caloric sweetener.

'Source: Authors' calculations based in part on data reported by Nielsen through its Homescan Services for all food categories, including beverages and alcohol for the years 2002 and 2018 from Nielsen Homescan Household Panel across the US market, The Nielsen Company, 2019. The conclusions drawn from the Nielsen data are those of the authors and do not reflect the views of Nielsen. Nielsen is not responsible for and had no role in, and was not involved in, analyzing and preparing the results reported herein.

${ }^{\mathrm{d} C S}$ Only = products that contain caloric sweeteners as the only type of sweetener.

NNS Only = products that contain nonnutritive sweeteners as the only type of sweetener

CS and NNS = products that contain both caloric and nonnutritive sweeteners.

${ }^{9} \mathrm{No} C \mathrm{CS}$ or NNS = products that neither contain caloric sweeteners or nonnutritive sweeteners. 
Table 3. Prevalence of $\mathrm{NNS}^{\mathrm{a}}$ consumption and $\mathrm{CS}^{\mathrm{b}}$ consumption by demographic subgroup of US households: a comparison of 2002 vs 2018 foods and beverages combined ${ }^{\text {cd }}$

\begin{tabular}{|c|c|c|c|c|c|c|c|c|}
\hline \multirow[b]{2}{*}{ Characteristics } & \multicolumn{2}{|c|}{ CS Only } & \multicolumn{2}{|c|}{ NNS Only ${ }^{f}$} & \multicolumn{2}{|c|}{ CS and NNS ${ }^{g}$} & \multicolumn{2}{|c|}{ No CS or NNS } \\
\hline & 2002 & 2018 & 2002 & 2018 & 2002 & 2018 & 2002 & 2018 \\
\hline Household with children $<18$ y old & 100.0 & 100.0 & 62.4 & 66.8 & 58.1 & 83.6 & 99.9 & 99.9 \\
\hline Household without children & 100.0 & 99.9 & 62.5 & 63.9 & 39.0 & 68.6 & 99.9 & 99.7 \\
\hline \multicolumn{9}{|l|}{ Head of household education } \\
\hline Less than high school diploma & 100.0 & 99.7 & 48.9 & 61.3 & 34.0 & 72.2 & 100.0 & 99.9 \\
\hline High school diploma & 100.0 & 100.0 & 62.7 & 66.6 & 45.8 & 76.1 & 99.9 & 99.8 \\
\hline More than high school diploma & 100.0 & 99.9 & 63.1 & 64.4 & 46.6 & 72.6 & 99.9 & 99.8 \\
\hline \multicolumn{9}{|c|}{ Household income (\% federal poverty level) } \\
\hline$<185$ & 100.0 & 99.9 & 55.4 & 61.4 & 43.0 & 75.3 & 99.9 & 99.8 \\
\hline 185-350 & 100.0 & 100.0 & 61.6 & 65.2 & 46.6 & 76.7 & 99.9 & 99.8 \\
\hline$>350$ & 100.0 & 99.9 & 67.4 & 66.7 & 47.1 & 70.1 & 99.9 & 99.8 \\
\hline \multicolumn{9}{|l|}{ Race or ethnicity } \\
\hline Hispanic & 100.0 & 99.9 & 60.3 & 62.3 & 49.9 & 75.3 & 99.9 & 99.6 \\
\hline Non-Hispanic white & 100.0 & 99.9 & 65.4 & 68.2 & 46.9 & 73.9 & 99.9 & 99.8 \\
\hline Non-Hispanic black & 100.0 & 100.0 & 47.5 & 56.9 & 37.3 & 74.6 & 99.8 & 99.7 \\
\hline Total sample & 100.0 & 99.9 & 62.5 & 64.9 & 46.0 & 73.5 & 99.9 & 99.8 \\
\hline
\end{tabular}

${ }^{a}$ NNS $=$ nonnutritive sweetener.

${ }^{\mathrm{b}} \mathrm{CS}=$ caloric sweetener.

'Source: Authors' calculations based in part on data reported by Nielsen through its Homescan Services for all food categories, including beverages and alcohol for the years 2002 and 2018 from Nielsen Homescan Household Panel across the US market, The Nielsen Company, 2019. The conclusions drawn from the Nielsen data are those of the authors and do not reflect the views of Nielsen. Nielsen is not responsible for and had no role in, and was not involved in, analyzing and preparing the results reported herein.

${ }^{\mathrm{d}}$ All comparisons between 2002 and 2018 were significant $(P<.05)$.

${ }^{\mathrm{e}} \mathrm{CS}$ Only $=$ products that contain caloric sweeteners as the only type of sweetener.

${ }^{\mathrm{f}} \mathrm{NNS}$ Only = products that contain nonnutritive sweeteners as the only type of sweetener.

${ }^{9} \mathrm{CS}$ and NNS = products that contain both caloric and nonnutritive sweeteners.

${ }^{\mathrm{h}}$ No CS or NNS = products that neither contain caloric sweeteners or nonnutritive sweeteners. 
Table 4. Volume per capita per day of products containing $\mathrm{NNS}^{\mathrm{a}}$ and $\mathrm{CS}^{\mathrm{b}}$ by demographic subgroup of US households: a comparison of 2002 vs 2018 foods ${ }^{c}$

\begin{tabular}{|c|c|c|c|c|c|c|c|c|}
\hline \multirow[b]{2}{*}{ Characteristics } & \multicolumn{2}{|c|}{ CS Only } & \multicolumn{2}{|c|}{ NNS Only ${ }^{\mathrm{e}}$} & \multicolumn{2}{|c|}{ CS and $\mathrm{NNS}^{f}$} & \multicolumn{2}{|c|}{ No CS or NNS ${ }^{g}$} \\
\hline & 2002 & 2018 & 2002 & 2018 & 2002 & 2018 & 2002 & 2018 \\
\hline Household with children $<\mathbf{1 8}$ y old & $179.4(0.8)$ & $162.7(0.8)$ & $1.5(0.0)$ & $1.9(0.0)$ & $3.2(0.0)$ & $5.4(0.1)$ & $81.2(0.4)$ & $112.3(0.6)$ \\
\hline Household without children & $255.7(0.9)$ & $263.9(0.9)$ & $4.3(0.1)$ & $4.9(0.1)$ & $5.1(0.1)$ & $10.0(0.1)$ & $134.0(0.5)$ & $193.5(0.6)$ \\
\hline \multicolumn{9}{|l|}{ Head of household education } \\
\hline Less than high school diploma & $246.9(5.4)$ & $272.6(8.9)$ & $3.4(0.4)$ & $4.5(1.0)$ & $3.6(0.3)$ & $8.3(1.0)$ & $126.9(3.2)$ & $174.5(6.2)$ \\
\hline High school diploma & $247.5(1.5)$ & $276.1(1.9)$ & $3.5(0.1)$ & $4.4(0.1)$ & $4.5(0.2)$ & $9.4(0.2)$ & $123.3(0.9)$ & $181.0(1.3)$ \\
\hline$<185$ & $217.0(1.7)$ & $249.1(1.7)$ & $2.4(0.1)$ & $3.4(0.1)$ & $3.5(0.1)$ & $7.9(0.2)$ & $107.3(1.0)$ & $156.9(1.2)$ \\
\hline $185-350$ & $237.2(1.2)$ & $226.8(1.1)$ & $3.5(0.1)$ & $3.7(0.1)$ & $4.2(0.1)$ & $8.0(0.1)$ & $117.3(0.7)$ & $158.2(0.8)$ \\
\hline$>350$ & $226.7(0.9)$ & $223.4(1.0)$ & $3.6(0.1)$ & $4.4(0.1)$ & $5.0(0.1)$ & $9.3(0.1)$ & $116.9(0.5)$ & $179.8(0.8)$ \\
\hline \multicolumn{9}{|l|}{ Race or ethnicity } \\
\hline Hispanic & $179.5(2.3)$ & $178.3(2.1)$ & $2.1(0.1)$ & $2.8(0.1)$ & $3.0(0.1)$ & $6.4(0.2)$ & $94.8(1.4)$ & $138.22(1.6)$ \\
\hline
\end{tabular}

\section{${ }^{a}$ NNS = nonnutritive sweetener.}

${ }^{\mathrm{b}} \mathrm{CS}=$ caloric sweetener.

'Source: Authors' calculations based in part on data reported by Nielsen through its Homescan Services for all food categories, including beverages and alcohol for the years 2002 and 2018 from Nielsen Homescan Household Panel across the US market, The Nielsen Company, 2019. The conclusions drawn from the Nielsen data are those of the authors and do not reflect the views of Nielsen. Nielsen is not responsible for and had no role in, and was not involved in, analyzing and preparing the results reported herein.

${ }^{\mathrm{d}} \mathrm{CS}$ Only = products that contain caloric sweeteners as the only type of sweetener.

${ }^{e} \mathrm{NNS}$ Only = products that contain nonnutritive sweeteners as the only type of sweetener.

${ }^{\mathrm{f}} \mathrm{CS}$ and NNS = products that contain both caloric and nonnutritive sweeteners.

${ }^{9}$ No $C S$ or NNS $=$ products that neither contain caloric sweeteners or nonnutritive sweeteners. 
Table 5. Volume per capita per day of products containing NNS ${ }^{a}$ and CS $^{b}$ by demographic subgroup of US households: a comparison of 2002 vs 2018 beverages ${ }^{c}$

\begin{tabular}{|c|c|c|c|c|c|c|c|c|}
\hline \multirow[b]{2}{*}{ Characteristics } & \multicolumn{2}{|c|}{ CS Only $^{d}$} & \multicolumn{2}{|c|}{ NNS Only } & \multicolumn{2}{|c|}{ CS and NNS ${ }^{f}$} & \multicolumn{2}{|c|}{ No CS or $\mathrm{NNS}^{\mathrm{g}}$} \\
\hline & 2002 & 2018 & 2002 & 2018 & 2002 & 2018 & 2002 & 2018 \\
\hline Household with children $<18$ y old & $196.3(1.7)$ & $96.2(1.0)$ & $49.7(0.9)$ & $44.4(0.8)$ & $5.2(0.2)$ & $20.9(0.4)$ & $180.4(1.4)$ & $169.7(1.3)$ \\
\hline Household without children & $216.0(1.7)$ & $148.3(1.2)$ & $127.4(1.7)$ & $121.0(1.3)$ & $7.1(0.2)$ & $30.9(0.4)$ & $275.5(1.8)$ & $285.6(1.6)$ \\
\hline \multicolumn{9}{|l|}{ Head of household education } \\
\hline Less than high school diploma & $263.6(10.3)$ & $175.8(10.2)$ & $86.8(7.1)$ & $85.5(9.2)$ & $6.2(1.2)$ & $33.2(2.7)$ & $291.0(16.8)$ & $314.2(16.2)$ \\
\hline High school diploma & $232.5(2.9)$ & $171.5(2.6)$ & $97.8(2.3)$ & $109.8(2.6)$ & $6.8(0.4)$ & $34.0(0.9)$ & $254.6(2.8)$ & $291.5(3.4)$ \\
\hline More than high school diploma & $197.2(1.4)$ & $116.1(0.9)$ & $100.0(1.4)$ & $91.6(1.0)$ & $6.2(0.2)$ & $25.2(0.3)$ & $233.1(1.4)$ & $230.9(1.2)$ \\
\hline \multicolumn{9}{|c|}{ Household income (\% federal poverty level) } \\
\hline$<185$ & $229.2(3.4)$ & $166.6(2.5)$ & $76.9(2.5)$ & $91.3(2.4)$ & $5.8(0.4)$ & $32.8(0.8)$ & $224.5(2.9)$ & $266.0(3.0)$ \\
\hline $185-350$ & $213.9(2.3)$ & $130.2(1.3)$ & $90.8(1.8)$ & $83.7(1.3)$ & $6.4(0.3)$ & $27.1(0.5)$ & $249.0(2.5)$ & $240.8(2.0)$ \\
\hline$>350$ & $192.9(1.7)$ & $111.4(1.2)$ & $118.3(1.9)$ & $108.2(1.5)$ & $6.7(0.2)$ & $24.9(0.5)$ & $243.7(1.8)$ & $242.5(1.7)$ \\
\hline \multicolumn{9}{|l|}{ Race or ethnicity } \\
\hline Hispanic & $201.5(4.4)$ & $105.9(2.5)$ & $55.0(2.5)$ & $53.7(2.0)$ & $6.8(0.5)$ & $22.7(0.8)$ & $194.7(4.1)$ & $217.5(3.9)$ \\
\hline Non-Hispanic white & $207.2(1.4)$ & $135.6(1.0)$ & $114.0(1.4)$ & $116.5(1.2)$ & $6.4(0.2)$ & $28.4(0.4)$ & $255.8(1.5)$ & $260.0(1.4)$ \\
\hline Non-Hispanic black & $231.8(4.1)$ & $152.3(2.9)$ & $44.2(1.9)$ & $54.4(1.8)$ & $6.7(0.4)$ & $32.2(0.8)$ & $188.8(3.1)$ & $239.6(3.8)$ \\
\hline Total sample & $208.8(1.3)$ & $131.4(0.9)$ & $99.0(1.2)$ & $96.1(0.9)$ & $6.4(0.2)$ & $27.6(0.3)$ & $240.7(1.3)$ & $247.9(1.2)$ \\
\hline
\end{tabular}

${ }^{a}$ NNS $=$ nonnutritive sweetener.

${ }^{6} \mathrm{CS}=$ caloric sweetener.

'Source: Authors' calculations based in part on data reported by Nielsen through its Homescan Services for all food categories, including beverages and alcohol for the years 2002 and 2018 from Nielsen Homescan Household Panel across the US market, The Nielsen Company, 2019. The conclusions drawn from the Nielsen data are those of the authors and do not reflect the views of Nielsen. Nielsen is not responsible for and had no role in, and was not involved in, analyzing and preparing the results reported herein.

${ }^{d} \mathrm{CS}$ Only = products that contain caloric sweeteners as the only type of sweetener.

eNNS Only = products that contain nonnutritive sweeteners as the only type of sweetener.

${ }^{\mathrm{f}} \mathrm{CS}$ and NNS = products that contain both caloric and nonnutritive sweeteners.

${ }^{9} \mathrm{No} C \mathrm{CS}$ or NNS = products that neither contain caloric sweeteners or nonnutritive sweeteners. 
Table 6. Prevalence of $\mathrm{NNS}^{\mathrm{a}}$ consumption and $\mathrm{CS}^{\mathrm{b}}$ consumption by demographic subgroup of US households: a comparison of 2002 vs 2018 beverages $^{\mathrm{cd}}$

\begin{tabular}{|c|c|c|c|c|c|c|c|c|}
\hline \multirow[b]{2}{*}{ Characteristics } & \multicolumn{2}{|c|}{ CS Only } & \multicolumn{2}{|c|}{ NNS Only ${ }^{f}$} & \multicolumn{2}{|c|}{ CS and NNS ${ }^{g}$} & \multicolumn{2}{|c|}{ No CS or NNS } \\
\hline & 2002 & 2018 & 2002 & 2018 & 2002 & 2018 & 2002 & 2018 \\
\hline Household with children $<18$ y old & 99.3 & 95.4 & 58.3 & 60.2 & 22.8 & 65.5 & 99.4 & 99.3 \\
\hline Household without children & 92.4 & 84.6 & 58.4 & 58.4 & 12.6 & 44.4 & 97.3 & 96.9 \\
\hline \multicolumn{9}{|l|}{ Head of household education } \\
\hline Less than high school diploma & 96.2 & 90.9 & 44.6 & 54.9 & 11.9 & 56.9 & 98.8 & 97.7 \\
\hline High school diploma & 95.4 & 89.3 & 58.3 & 60.6 & 15.3 & 54.8 & 98.2 & 97.7 \\
\hline More than high school diploma & 94.6 & 87.6 & 59.0 & 58.5 & 16.9 & 49.9 & 98.0 & 97.7 \\
\hline \multicolumn{9}{|c|}{ Household income (\% federal poverty level) } \\
\hline$<185$ & 95.6 & 90.8 & 51.3 & 55.7 & 15.1 & 57.6 & 97.8 & 97.6 \\
\hline $185-350$ & 95.5 & 90.2 & 57.2 & 59.0 & 16.8 & 55.2 & 98.1 & 98.0 \\
\hline$>350$ & 94.1 & 85.0 & 63.3 & 60.8 & 16.7 & 44.6 & 98.2 & 97.5 \\
\hline \multicolumn{9}{|l|}{ Race or ethnicity } \\
\hline Hispanic & 98.6 & 92.0 & 55.2 & 55.9 & 21.8 & 56.6 & 98.7 & 98.2 \\
\hline Non-Hispanic white & 94.0 & 86.6 & 61.5 & 62.5 & 15.1 & 49.2 & 98.1 & 97.7 \\
\hline Non-Hispanic black & 97.6 & 93.5 & 42.8 & 50.5 & 19.8 & 61.7 & 98.2 & 97.6 \\
\hline Total sample & 94.9 & 88.1 & 58.4 & 58.9 & 16.3 & 51.2 & 98.1 & 97.7 \\
\hline
\end{tabular}

${ }^{\mathrm{a} N N S}=$ nonnutritive sweetener

${ }^{\mathrm{b}} \mathrm{CS}=$ caloric sweetener.

'Source: Authors' calculations based in part on data reported by Nielsen through its Homescan Services for all food categories, including beverages and alcohol for the years 2002 and 2018 from Nielsen Homescan Household Panel across the US market, The Nielsen Company, 2019. The conclusions drawn from the Nielsen data are those of the authors and do not reflect the views of Nielsen. Nielsen is not responsible for and had no role in, and was not involved in, analyzing and preparing the results reported herein.

${ }^{\mathrm{d}}$ All comparisons between 2002 and 2018 were significant $(P<.05)$. Sample sizes of households were 39300 in 2002 and 61,101 in 2018.

${ }^{\mathrm{e}} \mathrm{CS}$ Only $=$ products that contain caloric sweeteners as the only type of sweetener

${ }^{\mathrm{f}} \mathrm{NNS}$ Only = products that contain nonnutritive sweeteners as the only type of sweetener.

${ }^{9} \mathrm{CS}$ and NNS = products that contain both caloric and nonnutritive sweeteners.

${ }^{\mathrm{h}}$ No CS or NNS = products that neither contain caloric sweeteners or nonnutritive sweeteners.

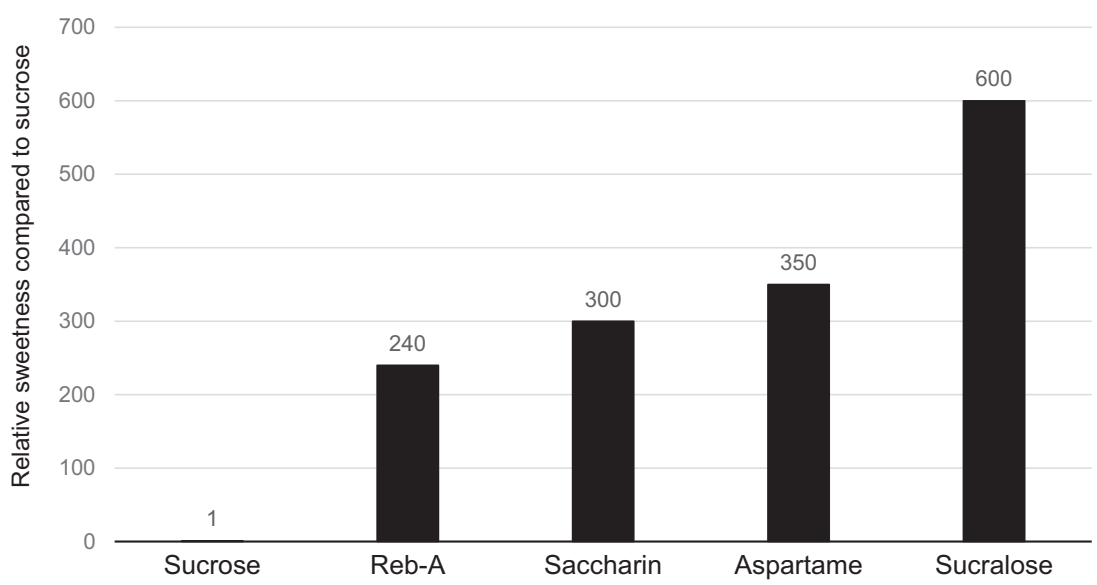

Figure 7. Sweetness of nonnutritive sweeteners relative to sucrose. Reb-A = rebaudioside A. 